\title{
Wire-Based Additive Manufacturing of Stainless Steel Components
}

\author{
Laser, arc, and electron beam sources were compared for freeform fabrication of \\ metal parts at high deposition rates
}

BY J. W. ELMER, J. VAJA, J. S. CARPENTER, D. R. COUGHLIN, M. J. DVORNAK, P. HOCHANADEL, P. GURUNG, A. JOHNSON, AND G. GIBBS

\begin{abstract}
Three different wire-fed additive manufacturing (AM) processes were employed to evaluate differences between laser, arc, and electron beam heat sources used for highdeposition-rate AM on the order of $1 \mathrm{~kg} / \mathrm{h}$. Optimum weld and build parameters were developed independently to match the characteristics of each heat source using $308 \mathrm{~L}$ stainless steel welding wire as the feedstock. Laser-wire AM was made with the lowest energy per unit length of weld and had the best control of the melt pool and surface finish. Wire arc-based AM had an intermediate energy per unit length of weld of approximately $5 \times$ that of the laser process, while electron beam wire AM had the highest energy per unit length of weld at approximately $10 \times$ that of the laser process. Analysis of the parts that were built included evaluation of mechanical properties and microstructures, and these properties are discussed with respect to the difference in input energy and cooling rates. Results show that all three processes build parts with properties that exceed those of annealed 304L wrought stainless steel. However, significant differences exist between the processes, and the results presented here can be used to help select the best wire-fed process for a given high-deposition-rate application.
\end{abstract}

\section{KEYWORDS}

- Wire-Fed Additive Manufacturing (AM) • Laser AM

- High-Deposition-Rate AM • Layer-by-Layer Fabrication

- Wire Arc AM • Mechanical Properties - Grain Texture

- Chemical Composition • Electron Beam AM • Welding

- Heat Input • Stainless Steels • Freeform Fabrication

- Anisotropy

\section{Introduction}

Wire-based additive manufacturing represents three of the four processes used to additively manufacture parts at high deposition rates. The three wire-based processes use either electron beam, laser beam, or arc heat sources to melt a wire feedstock, while the fourth high deposition rate process uses directed powders and laser heat sources (Refs. 1-4). High-deposition-rate additive manufacturing (AM) processes tend to use kilowatt (kW) or higher power levels, and can fabricate near-net-shaped parts at kilograms (kg) or multi $\mathrm{kg} / \mathrm{h}$ build rates with economic advantages over other AM methods (Ref. 5). These processes are distinguished from powder bed AM processes in that they are not confined to a box of prescribed dimensions, they have much higher deposition rates, have little or no restriction in component size, and are more economical in terms of cost per amount of material deposited (Refs. 1-5). Just like powder bed processes, wire-based AM can produce thin wall, thick wall, solid, and/or cast-like components without the need for a die, but with less precision due to the larger amount of material deposited per unit time. Nearly $100 \%$ of the wire is incorporated into the final part, making wire-fed technologies a more efficient use of feedstock than powder-based processes (Ref. 4). Components produced by wire-based AM can be compared to castings, but the microstructures are more refined than castings of similar size because the AM liquid weld pool is typically only a few millimeters $(\mathrm{mm})$ in diameter and is often orders of magnitude smaller than the finished part. The refined wire-based AM microstructures have smaller grains, less micro- and macro-segregation, and typically better mechanical properties than castings (Refs. 1, 2, 4). In addition, wire-based AM can be used to build onto, or modify, existing parts through cladding and hardfacing, and can also perform repair and maintenance of castings and other metal parts (Refs. 1-4).

The three wire-based AM processes are known by different names in the literature (Refs. 1-3), and will be referred to here as wire-fed laser AM (LAM-W), wire arc AM (WAAM), and wire-fed electron beam AM (EBAM-W [Ref. 6]). Each process uses a different power source, and each has advantages and disadvantages in terms of equipment and operating costs, microstructural control, heat input, surface finish of the part being made, and exposure to atmospheric contamination. Parts produced by the wire-based AM processes have the same nominal composition as the wire being used, with only minor variations in the composition due to different evaporation rates from the liquid weld pool of the various elements in the alloy (Ref. 7) or pickup of atmospheric contaminants (Refs. 8, 9). 

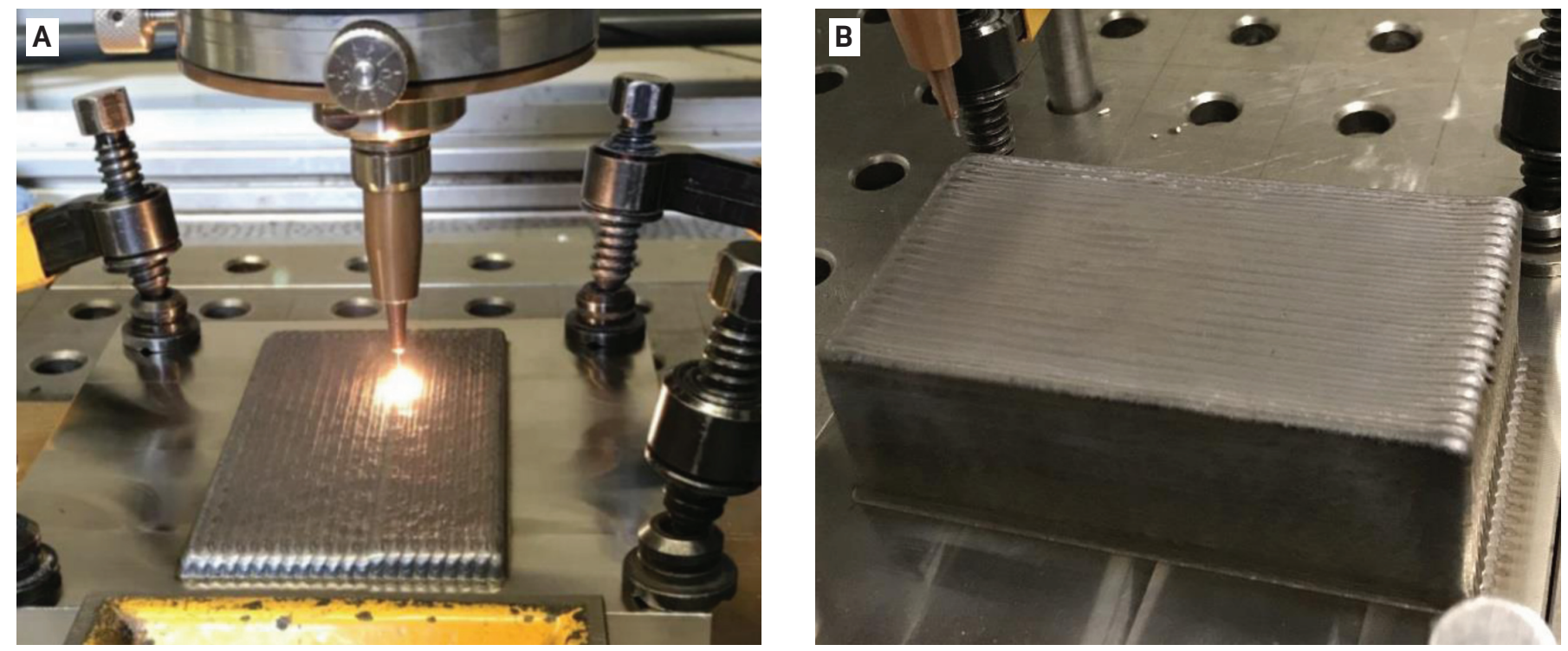

Fig. 1-Photographs of the LAM-W process showing: A - The system during the build; $B$ - the final LAM-W brick.

Wire-fed laser AM is a directed energy deposition method that couples conventional pulsed (Ref. 10) or continuous-wave (Refs. 11, 12) high-power laser sources with computer numerical control (CNC) machines and wire feeders to produce threedimensional (3D) parts layer by layer without the need of a mold (Ref. 4). Welding wire sources can be cold or heated, and are fed either coaxially (Refs. 13, 14) or from the side (Refs. 4 , 11,12 ) to add metal to the weld pool. Inert gas is used to help minimize interaction of the hot metal with the atmosphere. Lasers are high-energy-density heat sources that can be focused to small spot sizes and positioned with high accuracy. In this process, the laser heat source is used to create a molten weld pool while the welding wire is fed into this pool to add metal. Small laser spot sizes and low powers allow the LAM-W process to be operated with fine welding wire sizes that enable parts to be produced with higher resolution than the other two wire-based AM processes. For reactive metals such as titanium, the simple localized shielding gas often used with the LAM-W is insufficient to prevent oxidation. For such materials, more extended area shielding is required (Ref. 15). Laserassociated hazards and capital equipment costs make LAM-W a moderately high-cost process to operate per amount of metal deposited.

Wire arc AM is a freeform fabrication method that uses conventional wire-fed arc or plasma welding sources and modern robotic or $\mathrm{CNC}$ motion systems to produce 3D metal or alloy parts without a mold, but with less precision than the LAM-W process. Wire arc AM can be used with plasma arc, gas tungsten arc, or gas metal arc welding (GMAW) heat sources (Ref. 4). In the plasma arc and gas tungsten arc welding processes, the heat sources are used to create a weld pool, and the welding wire is fed independently into the weld pool to add filler metal to the build, much the same as LAM-W. This has the advantage of decoupling the wire feed from the arc power, but it also makes wire feeding more complicated because the welding wire must enter the weld pool at an angle to the torch. In the GMAW process, a coaxial wire is fed through the center of the torch and is an active element of the electrical circuit being directly coupled to the input power to the arc. The GMAW heat source is the easiest to implement with WAAM because of its coaxial nature and routine adaptation to $\mathrm{CNC}$ and robotic control systems, but it does not have the flexibility and independent control of the wire feed rate of the other arc heat sources. Wire arc AM is the least expensive of the three wire-fed processes due to the relatively low cost of the robotic systems and conventional arc welding power supplies. In addition, the energy utilization of arc-based AM is typically more than $90 \%$, which far exceeds that of laser and electron beam wire-based processes (Ref. 4). However, contact between the hot metal parts being built and the surrounding atmosphere can result in unwanted oxygen or nitrogen contamination. Such contamination can adversely affect the resulting mechanical properties of the build in oxygen-sensitive metals and alloys, such as titanium (Refs. 8, 9, 16-18). Handling such alloys requires special inert shielding gas considerations that increase the cost of the system, but can achieve near-wire compositions of the build with moderate inert gas purge conditions (Ref. 9).

Wire-fed electron beam AM is a directed energy deposition method that couples conventional electron beam welding equipment with a wire feeder, a stationary or movable electron beam gun, and additional $\mathrm{CNC}$ motion systems situated within the electron beam vacuum chamber to produce AM parts (Refs. 4, 19, 20). Like lasers, electron beams are high-energydensity heat sources that can focus its energy to small spot sizes, and they also have similar advantages. However, EBAMW has one central beam that prohibits the wire from being fed coaxially with the beam. Because of this, the wire is fed at an angle to the beam, which creates limitations on the direction and orientation of the gun relative to the part being built. Being in a vacuum, EBAM-W does not require any special shielding gas and produces parts with no chance of picking up unwanted contaminants. This is a big advantage, but vacuum chambers become large to include wire feeding and motion systems, which makes it the most expensive wire-fed process in terms of capital equipment and operating costs. Being in a vacuum, the parts cool more slowly than the other two 

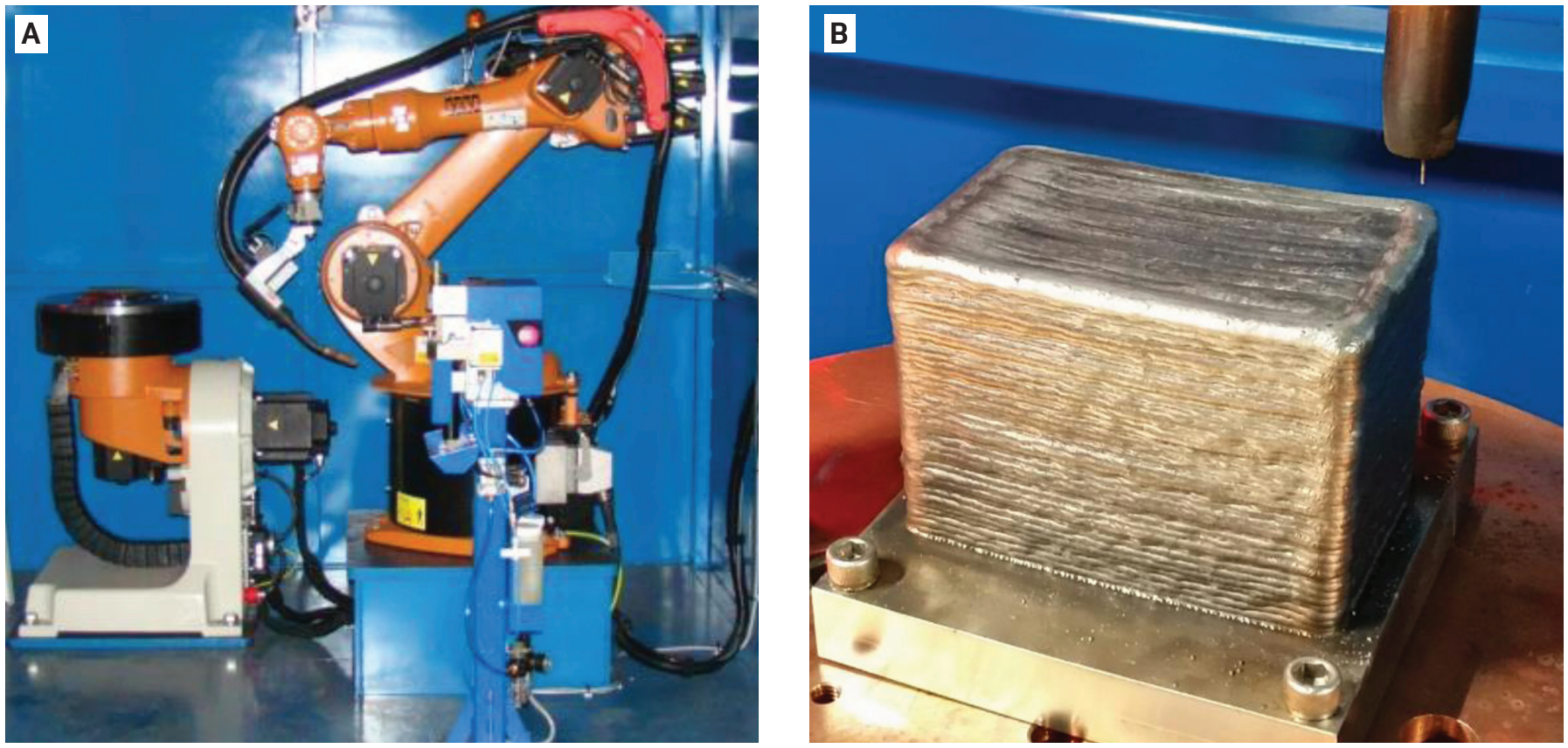

Fig. 2 - A - Eight-axis WAAM robotic cell with Fronius GMAW wire feed, power supply; B - completed solid WAAM brick made from $308 \mathrm{~L}$ SS welding wire.

processes and cannot be actively cooled through external convective inert gas. This makes the EBAM-W weld pool more difficult to control from layer to layer as well as more difficult to produce fine details. In addition, the microstructures created will tend to be coarser and more annealed, and the total build time will be increased relative to the other two processes.
This study comprises a collaboration between different facilities to evaluate the microstructure and mechanical properties of parts built using the three different wire-fed processes. Wire arc AM parts were built at Lawrence Livermore National Laboratory, Livermore, Calif., using a robotically positioned GMAW heat source. Wire-fed laser AM parts were built

Table 1-Compositions of the Starting Welding Wire and the AM Deposited Builds in wt-\% for Each of the Three Processes and Calculated Cr and Ni Equivalents from Ref. 27*

Elements

\begin{tabular}{|c|c|c|c|c|c|c|}
\hline & Wire & Build & Wire & Build & Wire & Build \\
\hline \multicolumn{7}{|c|}{ Ferrite Forming } \\
\hline $\mathrm{Cr}$ & 20.80 & 20.70 & 19.70 & 20.00 & 19.63 & 19.80 \\
\hline Mo & 0.130 & $<0.010$ & 0.200 & 0.110 & 0.070 & 0.100 \\
\hline $\mathrm{Ti}$ & 0.020 & - & 0.005 & - & 0.010 & 0.005 \\
\hline $\mathrm{Nb}$ & 0.010 & - & 0.010 & 0.030 & 0.010 & 0.060 \\
\hline $\mathrm{Mn}$ & 1.65 & 1.61 & 1.54 & 1.53 & 1.82 & 0.580 \\
\hline C & 0.021 & 0.020 & 0.021 & 0.023 & 0.017 & 0.024 \\
\hline $\mathrm{N}$ & 0.061 & 0.060 & 0.037 & 0.040 & 0.023 & 0.027 \\
\hline $\mathrm{Cu}$ & 0.020 & 0.020 & 0.090 & 0.110 & 0.310 & 0.080 \\
\hline \multicolumn{7}{|l|}{ Other } \\
\hline 0 & 0.005 & 0.047 & 0.007 & 0.041 & 0.005 & 0.002 \\
\hline Ni Eq. & 12.06 & 11.91 & 11.95 & 12.26 & 11.91 & 11.79 \\
\hline $\mathrm{Cr} / \mathrm{Ni} \mathrm{Eq.}$ & 1.83 & 1.80 & 1.75 & 1.71 & 1.73 & 1.78 \\
\hline
\end{tabular}

${ }^{*} \mathrm{Cr}_{\text {eq }}=\mathrm{Cr}+1.37 \mathrm{Mo}+1.5 \mathrm{Si}+2 \mathrm{Nb}+3 \mathrm{Ti}, \mathrm{Ni}_{\mathrm{eq}}=\mathrm{Ni}+0.31 \mathrm{Mn}+22 \mathrm{C}+14.2 \mathrm{~N}+\mathrm{Cu}$ 


\begin{tabular}{|c|c|c|c|c|c|c|c|c|c|c|c|}
\hline \multicolumn{3}{|c|}{ 308-L SS Wire Feed AM Results } & \multicolumn{3}{|c|}{ LAM-W } & \multicolumn{3}{|c|}{ WAAM } & \multicolumn{3}{|c|}{ EBAM-W } \\
\hline & & & No. Samples & Value & $\begin{array}{l}\text { Standard } \\
\text { Deviation }\end{array}$ & No. Samples & Value & $\begin{array}{l}\text { Standard } \\
\text { Deviation }\end{array}$ & No. Samples & Value & $\begin{array}{l}\text { Standard } \\
\text { Deviation }\end{array}$ \\
\hline \multirow[t]{14}{*}{ Build and Weld Parameters } & Heat source power & W & \multicolumn{3}{|c|}{1400} & \multicolumn{3}{|c|}{1980} & \multicolumn{3}{|c|}{3150} \\
\hline & Weld speed & $\mathrm{m} / \mathrm{min}$ & \multicolumn{3}{|c|}{1.2} & \multicolumn{3}{|c|}{0.32} & \multicolumn{3}{|c|}{0.25} \\
\hline & Energy/length of weld & $\mathrm{J} / \mathrm{mm}$ & \multicolumn{3}{|c|}{70} & \multicolumn{3}{|c|}{371} & \multicolumn{3}{|c|}{750} \\
\hline & Wire diameter & $\mathrm{mm}$ & \multirow{2}{*}{\multicolumn{3}{|c|}{$\begin{array}{r}1.1 \\
1.5\end{array}$}} & \multicolumn{3}{|c|}{1.1} & \multicolumn{3}{|c|}{1.5} \\
\hline & Wire speed & $\mathrm{m} / \mathrm{min}$ & & & & \multicolumn{3}{|c|}{3.8} & \multicolumn{3}{|c|}{1.4} \\
\hline & Max. deposition rate & kg/h & \multicolumn{3}{|c|}{$\begin{array}{l}1.5 \\
0.7\end{array}$} & \multicolumn{3}{|c|}{1.7} & \multicolumn{3}{|c|}{1.2} \\
\hline & Energy/amount deposited & $\mathrm{J} / \mathrm{gm}$ & \multicolumn{3}{|c|}{7463} & & 4166 & & & 9675 & \\
\hline & Brick size $(\mathrm{l} \times \mathrm{w} \times \mathrm{h})$ & $\mathrm{mm}$ & \multicolumn{3}{|c|}{$115 \times 65 \times 40$} & & $0 \times 80 \times$ & 95 & & $\times 110 \times 45$ & \\
\hline & Number of layers & & & 45 & & & 40 & & & 20 & \\
\hline & Layer height & $\mathrm{mm}$ & & 0.55 & & & 2.3 & & & 2.3 & \\
\hline & Bead overlap & $\%$ & & 47 & & & 50 & & & 50 & \\
\hline & Weld bead size $(w \times d)$ & $\mathrm{mm}$ & & $\sim 3.0 \times 1.0$ & & & $\sim 9 \times 4.5$ & & & $\sim 10 \times 6$ & \\
\hline & Weld cross section area & $\mathrm{mm}^{2}$ & & $\sim 2.5$ & & & $\sim 25$ & & & $\sim 45$ & \\
\hline & Shielding gas & & & Argon & & Ar- & $\mathrm{He}-0.5 \%$ & $\mathrm{CO}_{2}$ & & -5 Torr vac. & \\
\hline Build Properties & Microhardness & HV & 15 & 214 & 9.4 & 19 & 205.6 & 9.1 & 14 & 172.6 & 13.6 \\
\hline & Macrohardness & HRB & 6 & 92.5 & 2.3 & 8 & 88.2 & 1.3 & 12 & 83.1 & 2.2 \\
\hline & Ferrite content & FN & 12 & 9.1 & 0.22 & 8 & 7.7 & 0.23 & 15 & 4.9 & 0.8 \\
\hline & Primary dendrite arms & $\mu \mathrm{m}$ & & $6.0-8$ & & & 18-25 & & & $20-26$ & \\
\hline & Secondary dendrite arms & $\mu \mathrm{m}$ & & $3.0-4$ & & & $7.0-9$ & & & $8.0-10$ & \\
\hline & Oxygen content & wt-\% & & 0.047 & & 3 & 0.041 & 0.002 & & 0.002 & \\
\hline & $\mathrm{Cr} / \mathrm{Ni}$ equivalent: build & ratio & & 1.80 & & & 1.77 & & & 1.78 & \\
\hline Tensile Test Results & Gauge length & $\mathrm{mm}$ & & 16 & & & 25 & & & 16 & \\
\hline & Diameter & $\mathrm{mm}$ & & 4 & & & 6.4 & & & 3.18 & \\
\hline & Strain rate & /s & & $1.5 \times 10^{-3}$ & & & $1.5 \times 10^{-3}$ & & & $1.0 \times 10^{-3}$ & \\
\hline & Extensometer length & $\mathrm{mm}$ & & 12.5 & & & 25 & & & 12.5 & \\
\hline & Yield stress & $\mathrm{MPa}$ & & & & 3 & 323.4 & 18.2 & 3 & 308.9 & 7 \\
\hline Vertical & UTS & $\mathrm{MPa}$ & & & & 3 & 551.6 & 3.1 & 3 & 528.8 & 14 \\
\hline & Modulus (0.1\%) & $\mathrm{GPa}$ & & & & 3 & 166.2 & 9.6 & & 172.4 & \\
\hline & Elongation to failure & $\%$ & & & & 3 & 51.6 & 12.7 & 3 & 50.7 & 6 \\
\hline Longitudinal & Yield stress & $\mathrm{MPa}$ & 14 & 444.0 & 6.6 & 4 & 343.4 & 15.7 & 7 & 283.4 & 21 \\
\hline & UTS & $\mathrm{MPa}$ & 14 & 617.8 & 7.5 & 4 & 570.9 & 8.1 & 7 & 565.4 & 14 \\
\hline & Modulus (0.1\%) & $\mathrm{GPa}$ & 14 & 133.1 & 8.8 & 4 & 162.0 & 9.3 & & 158.5 & \\
\hline & Elongation to failure & $\%$ & 14 & 47.7 & 2.7 & 4 & 51.9 & 2.3 & 7 & 46.3 & 4 \\
\hline & Yield stress & $\mathrm{MPa}$ & 8 & 482.0 & 17.3 & 4 & 382.0 & 3.8 & 7 & 342.0 & 41 \\
\hline Transverse & UTS & $\mathrm{MPa}$ & 8 & 657.8 & 12.1 & 4 & 626.8 & 19.0 & 7 & 584.0 & 28 \\
\hline & Modulus (0.1\%) & $\mathrm{GPa}$ & 8 & 162.0 & 12.1 & 4 & 211.7 & 22.2 & & 220.6 & \\
\hline & Elongation to failure & $\%$ & 8 & 46.2 & 8.1 & 4 & 41.7 & 2.7 & 7 & 49.6 & 5 \\
\hline
\end{tabular}

through the Aldermaston Weapons Establishment, Reading, UK. Wire-fed electron beam AM parts were built by Los Alamos National Laboratory, Los Alamos, N.Mex. Similarly sized rectangular bricks weighing about $5 \mathrm{~kg}$ each were made by each process from 308L stainless steel (SS) wire. The resulting builds were characterized to compare build parameters and evaluate microstructure, composition, and tensile properties along different orientations relative to the AM build geometry. Results from this study are useful for comparing relative advantages and disadvantages of each process.

\section{Experimental Methods}

\section{Laser Wire Additive Manufacturing}

The LAM-W samples were produced by Laserline under subcontract to the Aldermaston Weapons Establishment (Ref. 21) using an LDF 5000-30 laser with a Fraunhofer coaxial wire-feed head. The equipment, shown in Fig. 1, features an optical setup where the collimated laser beam is split into three separate beams that subsequently converge onto the welding wire at a circular focal point. The setup is such that the wire is fed exactly onto the central axis of the converging laser beams, thereby creating a weld pool independent of the welding direction or gravity. Figure $1 \mathrm{~A}$ shows the brick at an intermediate stage of completion, and Fig. 1B shows the completed brick. Wire-fed laser AM was used with a 1.1-mm-diameter 308L SS welding wire having the composition shown in Table 1 to build a $115 \times 65 \times 40 \mathrm{~mm}$ brick onto a $25-\mathrm{mm}$-thick $304 \mathrm{~L}$ SS substrate. Note that 308L SS has a similar composition to 304L SS, and is readily available in 1.1-mm-diameter welding wire but not available in other forms, hence 304L was used as the starting build plate.

The LAM-W builds were made at a weld travel speed of $1.2 \mathrm{~m} / \mathrm{min}$, which is the highest of the three processes. The remaining build and welding parameter data are summarized in Table 2 for a laser spot size of $2 \mathrm{~mm}$ diameter. The 


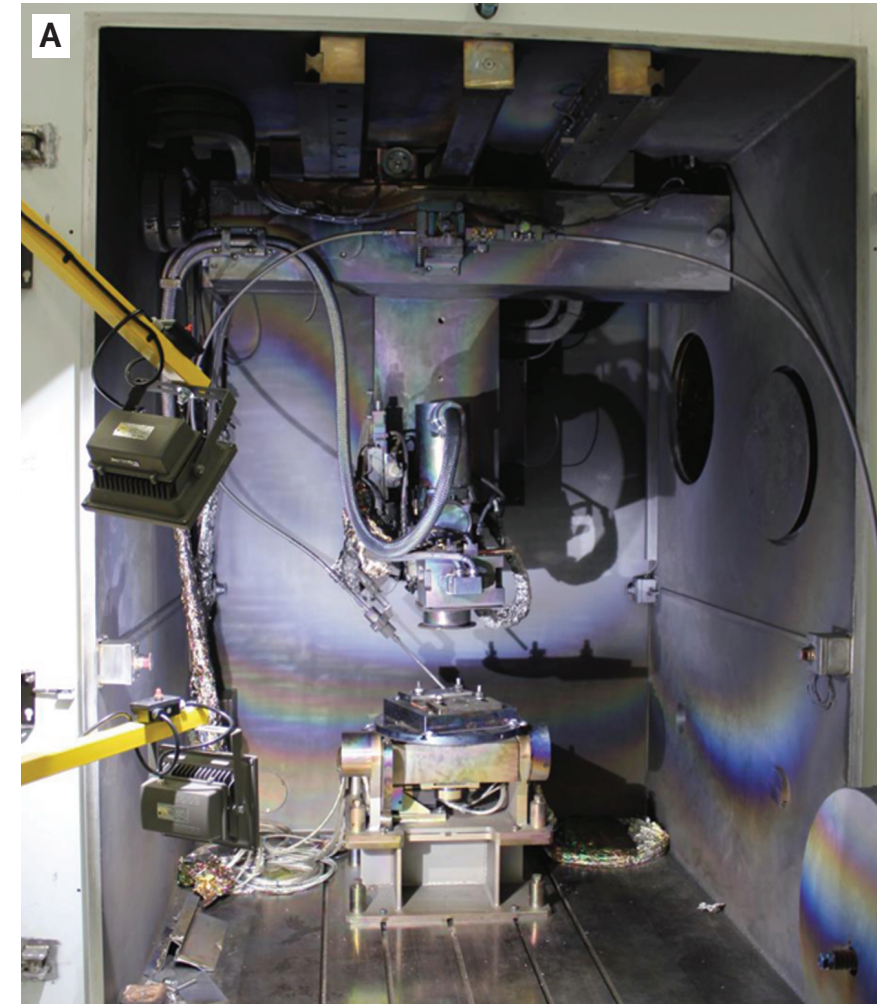

brick was built with the deposition strategy, which altered the direction of travel between passes using nearly $50 \%$ overlap of $1.4 \mathrm{~mm}$ for the 3-mm-wide weld beads. At the end of each layer, the laser was returned to the initial starting position, and then offset $1.0 \mathrm{~mm}$ upward, which was then used as the starting point on the next layer. The laser was constantly powered through the entire build stage. To avoid overheating the pad, the laser power was reduced from a starting power of 1600 to 1200 W. A 200-W reduction in power was applied in two stages, first after the third layer and one after the sixth layer. Note that the power and energy calculations presented in Table 2 assume the average laser power of $1400 \mathrm{~W}$. The final brick consisted of 45 layers, had a maximum deposition rate of $0.7 \mathrm{~kg} / \mathrm{h}$, and was made at an energy per unit length of $70 \mathrm{~J} / \mathrm{mm}$.

\section{Wire Arc Additive Manufacturing}

Wire arc AM was performed using an eight-axis robotic welding system to fabricate shapes from 1.1-mm 308L SS welding wire having the composition listed in Table 1 . The robotic cell with a Fronius cold metal transfer (CMT) GMAW power supply and gun are shown in Fig. 2A. This setup was used to fabricate a $130 \times 80 \times 95 \mathrm{~mm}$ solid brick on 1-in.thick 304L SS base plate, as shown in Fig. 2B after wire brushing to remove the welding soot. Summarized in Table 2 , the welding parameters consisted of a constant wire feed speed of $3.8 \mathrm{~m} / \mathrm{min}$, an average welding voltage of approximately $18 \mathrm{~V}$, and a current of $110 \mathrm{~A}$, which is about $1 / 2$ the maximum level of the power supply. The power supply was run in pulsed CMT mode using Ar- $29.5 \% \mathrm{He}-0.5 \% \mathrm{CO}_{2}$ trimix shielding gas at $30 \mathrm{ft}^{3} / \mathrm{h}$ flow rate through the welding gun. Cooling between layers used a side shield of argon gas flow-

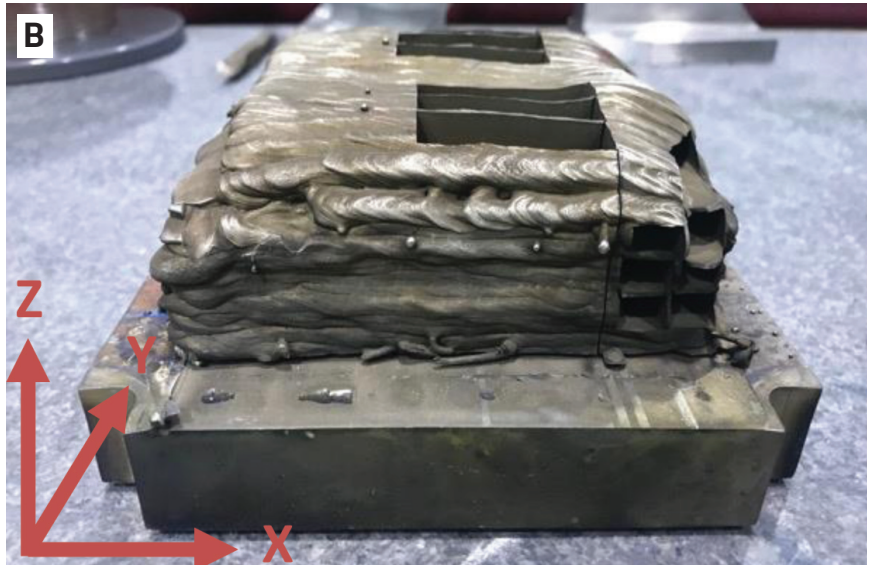

Fig. 3-A - Photograph of the vacuum chamber, welding gun, and wire feeder of the EBAM-W system; B - image of the 308L EBAM-W build with blanks cut out for tensile samples.

ing at $40 \mathrm{ft}^{3} / \mathrm{h}$ while the brick rotated at a constant speed.

The WAAM builds were made at a weld travel speed of $0.32 \mathrm{~m} / \mathrm{min}$, which produced a weld pool approximately 9 $\mathrm{mm}$ in diameter. A layer-by-layer, dam-and-fill procedure was used to create the brick shape with straight edges, whereby a perimeter frame was made first on each layer to define the edges of the brick, and then the inside of the frame was filled using a serpentine pattern with a bead overlap of approximately $50 \%$. At the completion of each layer, argon gas was blown onto the brick for approximately $1 \mathrm{~min}$ to help cool the brick. In addition, wire brushing after each layer was performed to clean the surface to minimize entrapment of surface oxides during the build. A total of approximately $5 \mathrm{~min}$ of welding time and $5 \mathrm{~min}$ of cooling/cleaning time was required per layer. The brick consisted of 40 layers at 2.3-mm offset height per layer. The build was made with a deposition rate of $1.7 \mathrm{~kg} / \mathrm{h}$ if the weld was run continuously, and at an energy per unit length of $371 \mathrm{~J} / \mathrm{mm}$. This energy per length of weld was approximately $5 \times$ that of the LAM-W build, largely due to its lower speed, and produced larger resulting weld pools.

\section{Electron Beam Wire Additive Manufacturing}

Wire-fed electron beam AM builds were made on a Sciaky low-voltage system (60 KV maximum) using 308L SS welding wire with the composition listed in Table 1 . The system is shown in Fig. 3A and employed 1.5-mm-diameter welding wire to make a $110 \times 110 \times 40 \mathrm{~mm}$ brick using the build and welding parameters summarized in Table 2 . The EBAM-W wire diameter was about $40 \%$ larger than the welding wires used for the other two processes, and it required $3.2 \mathrm{~kW}$ of power ( $30 \mathrm{kV}$ at $105 \mathrm{~mA}$ ), which is the highest of the three processes. In EBAM-W, the wire cannot be coaxially located to avoid interference with the electron beam, and is instead fed into the weld pool from the side or directly in front of the beam. This wire-feed orientation made it more difficult to turn corners and reverse directions than with coaxial-fed processes, and required a different scanning strategy. Figure $3 \mathrm{~B}$ shows the completed brick that was built on a 304L SS substrate with 20 layers each approximately $2 \mathrm{~mm}$ high. The 


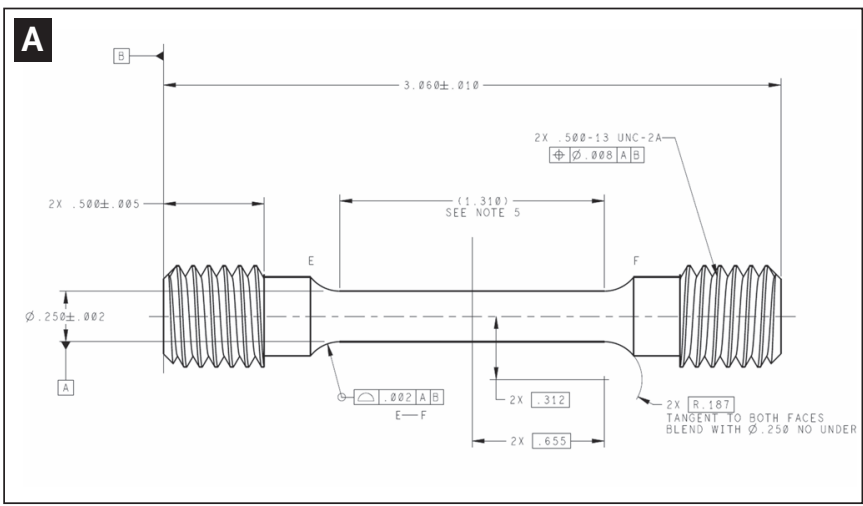

Fig. 4-A - Tensile bar configuration from the WAAM brick (dimensions in inches), which is similar to the other tensile bars but larger in size; $B$ - tensile bar orientation relative to the brick dimensions.

weld sequence used individual linear weld bead segments that were all made in the same direction and overlapped approximately $50 \%$ at $4.5-\mathrm{mm}$ distance between beads.

The EBAM-W builds were made at a weld travel speed of $0.25 \mathrm{~m} / \mathrm{min}$, which is the slowest of the three processes. In this process, the beam was defocused 30 increments from sharp at a 250-mm work distance and distributed over several $\mathrm{mm}$ diameter using a deflection pattern with nine concentric circles of 1000 points each. This pattern diffused the energy into a large enough area to facilitate the melting of the welding wire and maintain the weld pool to provide the additive deposit. This method is common to the process, which seeks to deposit large volumes of material for the development of preforms that are then machined to final dimensional products. The brick was made with a maximum deposition rate of $1.2 \mathrm{~kg} / \mathrm{h}$ and at an energy per unit length of $750 \mathrm{~J} / \mathrm{mm}$. This energy per length of weld is approximately $2 \times$ that of the WAAM process and $10 \times$ that of the LAM-W process. Owing to the nature of the deposit size, heat input, and lack of convective cooling within a vacuum, the EBAM-W deposits had the slowest cooling of the three processes, with corresponding changes to the microstructure.

\section{Mechanical Testing and Characterization}

Coupons were removed from each of the three bricks for mechanical property testing and microstructural characterization. The tensile samples were prepared by electrical discharge machining extraction of blanks from the brick, followed by standard milling and turning to produce ASTMtype round tensile bars as large as possible given the dimensions of the bricks. Since the bricks varied in size, different sized samples were produced with the dimensions given in Table 2. The largest sample was from the WAAM brick, which measured 3 in. (76 mm) long and had a 0.25-in. (6.4$\mathrm{mm}$ ) reduced diameter cross section, as illustrated in Fig. $4 \mathrm{~A}$. The tensile bars were removed from three principal orientations of the brick as indicated in Fig. 4B, and labeled vertical (V) perpendicular to the layers, longitudinal (L) parallel to the welding direction, and transverse $(\mathrm{T})$, which is the weld overlap direction perpendicular to and in plane with the longitudinal orientation. The tensile bars were tested using servo-hydrolytic machines by each respective facility at room temperature and a strain rate of $1.5 \times 10^{-3} / \mathrm{s}$.
From these tests, yield strength, ultimate tensile strength, elastic modulus, and elongation to failure were measured (see Table 2).

Additional characterization was performed on samples from each brick to measure residual ferrite, Vickers microhardness, and Rockwell B macrohardness, as summarized in Table 2. All of the samples were metallographically prepared using standard cross sectioning and polishing methods, and etched electrolytically in an oxalic acid solution to reveal the microstructural details. The delta ferrite was measured using a Magne-Gage and a No. 2 magnet with randomly spaced readings taken on the build cross section. Hardness measurements were made using calibrated testing machines, with the average of eight or more samples per brick being reported. In addition, the chemical composition of the builds were measured to see how they compared to the welding wire they were made from. Chemical analysis was performed on subsurface samples removed from the bricks using calibrated LECO instruments to determine oxygen, nitrogen, carbon, and sulphur content to better than 0.1-ppm precision, while inductively coupled plasma optical emission spectroscopy was used to measure the other elements.

\section{Results}

\section{Laser Wire Additive Manufacturing}

Macrostructures and microstructures of the LAM-W brick are shown in Fig. 5. An overall cross-sectional view of the entire 65 -mm-wide by 40 -mm-high brick is shown in Fig. 5A. This photograph shows the T-V plane that is perpendicular to the longitudinal welding direction. The faint boundaries of the 45 layers that make up the brick can be seen as horizontal lines, and the remnants of overlapping beads appear as crescent shapes, which create a pattern that dips from the upper left to the lower right at an angle of approximately $25 \mathrm{deg}$. Superimposed on these patterns are columnar grain boundaries that trend upward, with the larger grains continuing through ten or more layers. The columnar grains appear to be larger on the top surface of the brick than on the bottom, i.e., there appears to be a macroscopic growth of the columnar grains going on as additional layers are built on top of each other. Figure 5B shows a close-up 

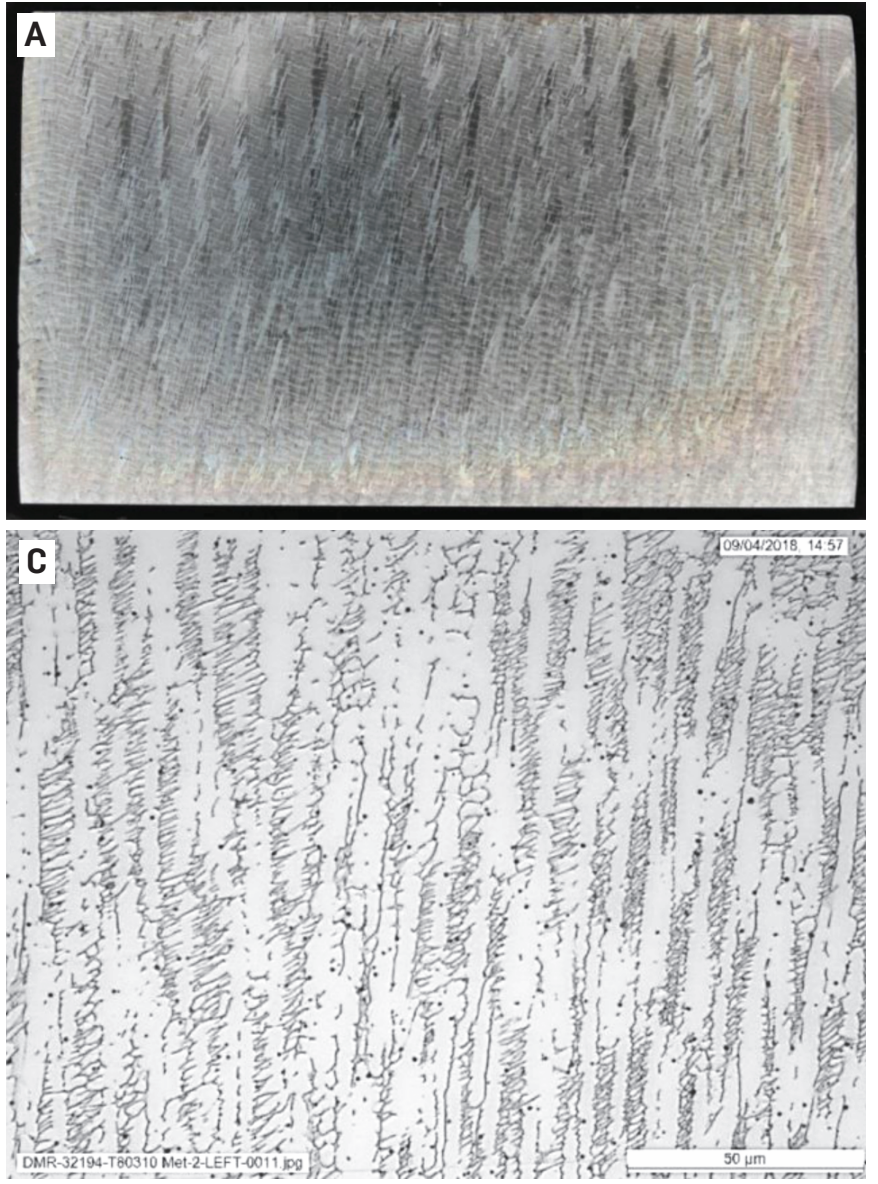

image of the macroscopic grain structure of the brick, where the aforementioned details of the individual overlapping beads and the columnar grains can be seen more closely.

A typical microstructure from this plane is shown in Fig. $5 \mathrm{C}$ at a much higher magnification. In this microstructure, remnants of the dark etching delta ferrite dendrites are aligned nearly vertical to the build direction, and have a primary dendrite arm spacing (DAS) range of 6-8 micron. The resulting ferrite microstructure shows both vermicular and lacy morphologies as a result of primary ferrite solidification followed by partial transformation of the ferrite to austenite (Refs. 22-24). The residual ferrite content of the brick was measured to be $9.1 \mathrm{FN}$ for the wire that had a $\mathrm{Cr} / \mathrm{Ni}$ equivalent ratio of 1.83 , which is on the higher side, but in the range for welds made from 308L SS welding wire. The oxygen content was measured to be $0.047 \mathrm{wt}-\%$, which is approximately $10 \times$ that of the starting material and is undesirable. The hardness values of the LAM-W brick of HRB = 92.5 and $H V=214$ are typical for SS welds (Ref. 22), and are higher than annealed 304L SS minimum values of $\mathrm{HRB}=70$ and $\mathrm{HV}=160$.

Tensile bars were removed from the LAM-W brick along the transverse and longitudinal directions, but the brick was not tall enough to remove vertically oriented tensile bars. These samples were mechanically tested to failure. A photograph of a typical broken tensile bar is shown in Fig. 6. The sample displayed dimpling along the gauge length, and the final fracture was a cup- and cone-type geometry. The stress-strain curves for the 308L LAM-W brick are shown in Fig. 7 , and the tensile data are summarized in Table 2. These

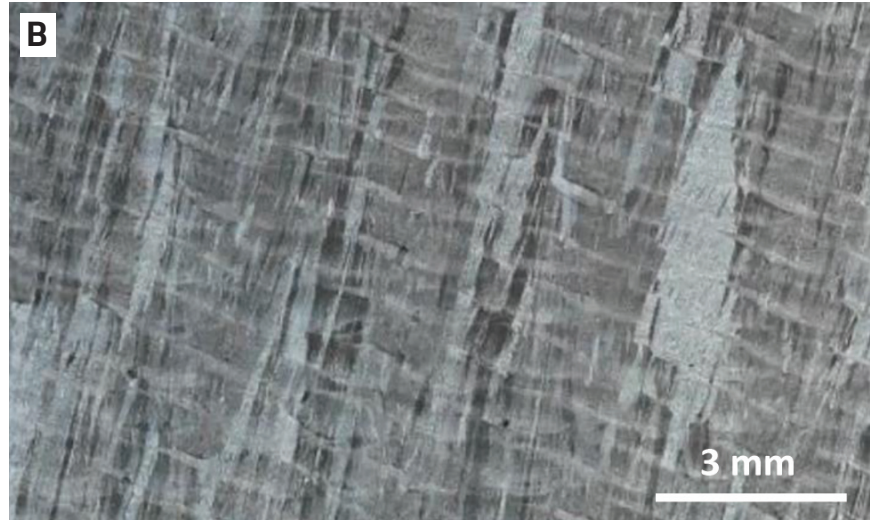

Fig. 5 - LAM-W microstructures from Laserline: A - Photograph of the polished and etched 115 - $m m$-wide cross section; $B$ - photograph of the weld bead and grain structure detail; $C$ residual delta ferrite microstructure at high magnification.

data indicate the strongest orientation was in the transverse direction, where the average yield strength increased from 444 (longitudinal) to $482 \mathrm{MPa}$ (transverse). Similar results were obtained for the average ultimate strength, which increased from 618 (longitudinal) to $658 \mathrm{MPa}$ (transverse). The average elongation values varied from 46.2 (transverse) to $47.7 \%$ (longitudinal). In addition to the tensile strength and elongation, the modulus of elasticity was highest in the transverse direction at $162 \mathrm{GPa}$ as compared to the longitudinal direction at $133 \mathrm{GPa}$.

\section{Wire Arc Additive Manufacturing}

A cross-sectional view of the entire 80-mm-wide by 95$\mathrm{mm}$-high brick is shown in Fig. 8A. This photograph is of the polished and etched surface and shows the T-V plane that is perpendicular to the longitudinal welding direction, just as was shown for the LAM-W brick. The faint boundaries of the overlapping individual weld beads were visible in each layer, and were significantly larger than those of the LAM-W sample. Figure 8B shows a close-up image of the macroscopic grain structure of the brick, where the aforementioned details of the overlapping beads and the columnar grains can be seen more closely. The individual grains can be seen growing upward through the beads. One difference between the macrostructure of the WAAM and LAM-W parts is that the larger columnar grains appeared to grow through multiple layers of the LAM-W.

A typical microstructure from this plane is shown in Fig. $8 \mathrm{C}$ at a much higher magnification from a region where weld beads are overlapping. Delta ferrite dendrites were aligned near vertical in the build direction, and the ferrite microstructure showed both vermicular and lacy morphologies, just as was observed in the LAM-W part, but with a larger primary DAS range of $18-25$ microns. Other parameters that were measured are summarized in Table 2, including the residual ferrite content, micro- and macrohardness, and oxygen content of the build. The residual ferrite content of the brick was measured to be $7.7 \mathrm{FN}$ for the wire that had a $\mathrm{Cr} / \mathrm{Ni}$ equivalent ratio of 1.75 , which is typical for welds made from 308L SS welding wire. The oxygen content was measured to be $0.041 \mathrm{wt}-\%$, which is approximately $10 \times$ that 


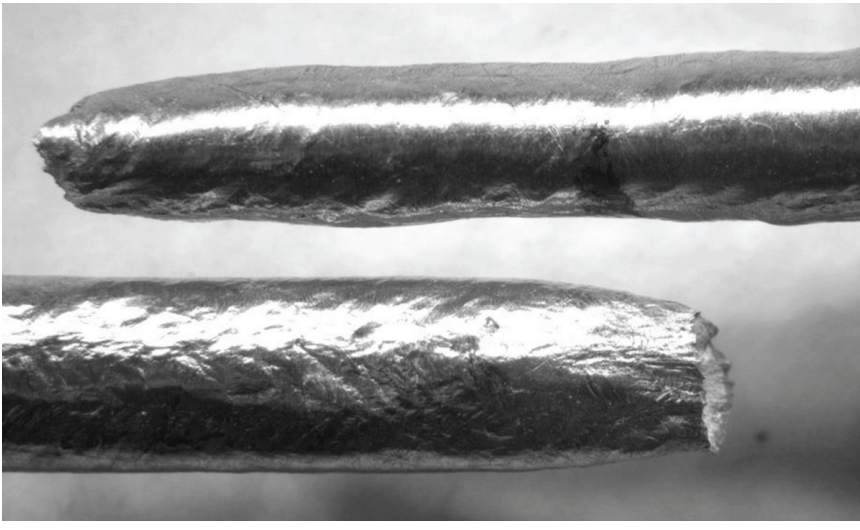

Fig. 6 - Photograph of a failed LAM-W tensile bar showing a dimpled surface along the gauge length of the sample.

of the starting material and is undesirable. The hardness values of the WAAM brick of $\mathrm{HRB}=88.2$ and $\mathrm{HV}=206$ were slightly lower than the LAM-W brick.

Tensile bars were removed from the WAAM brick along the transverse, longitudinal, and vertical directions and mechanically tested to failure. Figure 9 shows a photograph of a typical broken WAAM tensile sample. This sample had a rougher surface than the LAM-W tensile bar. Inhomogeneous deformation observed in the WAAM sample was the result of the large grains relative to the diameter of the tensile bar, and will be discussed in more detail later. In addition, fine parallel wavy lines are clearly visible on the surface of the sample, which is the result of slip bands forming in the large grains. The slip bands were more obvious in the WAAM sample than in the LAM-W sample, most likely due to larger grains that are produced by WAAM than LAM-W. The stress-strain curves for the 308L WAAM brick are shown in Fig. 10 for each of the three orientations, and the tensile data are summarized in Table 2. The data shows the strongest orientation was in the transverse direction, and the other two orientations were more than $10 \%$ weaker and similar to each other. The range of the average yield strengths varied from 323 (vertical) to $382 \mathrm{MPa}$ (transverse), while the range of the average ultimate strengths varied from 552 (vertical) to $627 \mathrm{MPa}$ (transverse). The average elongation values varied from 40.7 (transverse) to $51.9 \%$ (longitudinal). In addition to the tensile strength and elongation, the modulus of elasticity showed considerable variation among the different orientations. The modulus ranged from 162 to $212 \mathrm{GPa}$, and was highest in the transverse direction, while the other orientations averaged about $160 \mathrm{GPa}$.

\section{Electron Beam Wire Additive Manufacturing}

Macrostructures and microstructures of the EBAM-W brick are shown in Fig. 11. An overall cross-sectional view of the entire 110 -mm-wide by $45-\mathrm{mm}$-high brick is shown in Fig. 11A, which is of the polished and etched surface. The photograph shows the T-V plane that is perpendicular to the longitudinal welding direction, just as was shown for the other bricks. There was some 90 -deg rotation of the weld beads required to make this brick, where the section shows both longitudinal and cross-sectional boundaries of the welds. Columnar grains can be seen propagating from the bottom to the top of the brick. The faint boundaries of the

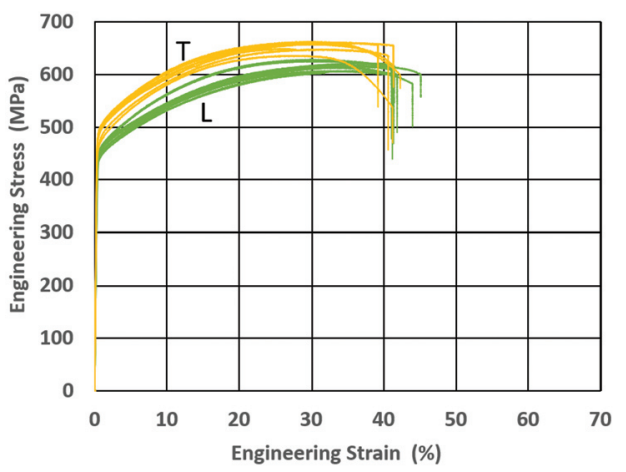

Fig. 7- LAM-W tensile test results for the transverse $(T)$ and longitudinal $(L)$ orientations, showing the transverse orientation to have the highest yield and ultimate strengths.

overlapping individual weld beads were visible in each layer and significantly larger than those of the other bricks.

Figure 11B shows a close-up image of the macroscopic grain structure of the brick and individual weld bead boundaries. A typical microstructure from the EBAM-W brick is shown in Fig. $11 \mathrm{C}$ at a much higher magnification. Delta ferrite dendrites were aligned near vertical in the build direction, and the ferrite microstructure showed both vermicular and lacy morphologies just as was observed in the other bricks, but with a primary DAS range similar to the WAAM brick but slightly larger at 20-26 microns. Other parameters that were measured are summarized in Table 2, including the residual ferrite content, micro- and macrohardness, and oxygen content of the build. The residual ferrite content of the brick was measured to be $4.9 \mathrm{FN}$ for the wire that had a $\mathrm{Cr} / \mathrm{Ni}$ equivalent ratio of 1.73 . This ferrite content is lower than would be expected for 308L SS, and will be discussed in more detail later. The oxygen content was measured to be $0.0007 \mathrm{wt}-\%$, which is identical to that of the starting welding wire, and significantly lower than the other two processes. The hardness values of the EBAM-W brick of $\mathrm{HRB}=83.1$ and $\mathrm{HV}=172.6$ is the lowest of the three processes, but still harder than annealed 304L SS.

Tensile bars were removed from the EBAM-W brick along the transverse, longitudinal, and vertical directions and mechanically tested to failure. Figure 12 shows a photograph of the necked region of a typical broken EBAM-W tensile sample. This sample looks similar to those of the other techniques, but the surface is even more dimpled where the large grains relative to the sample cross section create a lumpy appearance along the gauge length and in the necked region of the tensile bar. As in the case with the WAAM sample, slip bands can be observed, but they are only obvious in the necked portion of the EBAM-W sample. The stress-strain curves for the EBAMW brick are shown in Fig. 13, and the tensile data are summarized in Table 2 . The data show the strongest orientation is again in the transverse direction. The range of the average yield strengths varied from 283 (longitudinal) to $342 \mathrm{MPa}$ (transverse), while the range of the average ultimate strengths varied from 529 (vertical) to $584 \mathrm{MPa}$ (transverse). The average elongation values varied from 46.3 (longitudinal) to $50.7 \%$ (vertical). In addition to the tensile strength and elongation, the modulus of elasticity also showed considerable variation. 


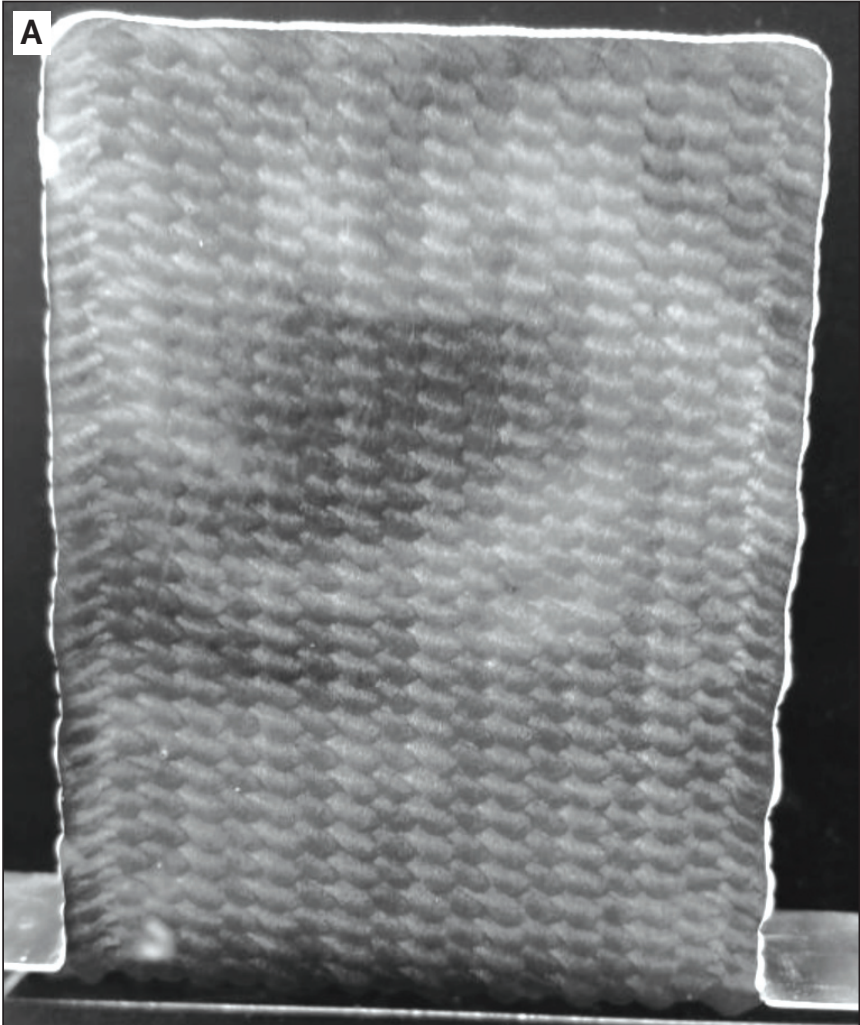

Fig. 8 - WAAM microstructures: A - Photograph of polished and etched $80-\mathrm{mm}$-wide cross section of the brick; $B$ - photograph of the weld bead and grain structure detail; $C$ - residual delta ferrite microstructure at high magnification.

The modulus of the EBAM-W samples ranged from 158.5 to 220.6 GPa. The highest value of 220.6 GPa was in the transverse direction and very similar to the WAAM value of 212 GPa. The other two EBAM-W orientations averaged 165.4 $\mathrm{GPa}$, which is also very similar to the WAAM build of $160 \mathrm{GPa}$.

\section{Discussion}

\section{Microstructure}

The three wire-based AM processing methods differ mainly in terms of welding travel speed and heat input per unit length
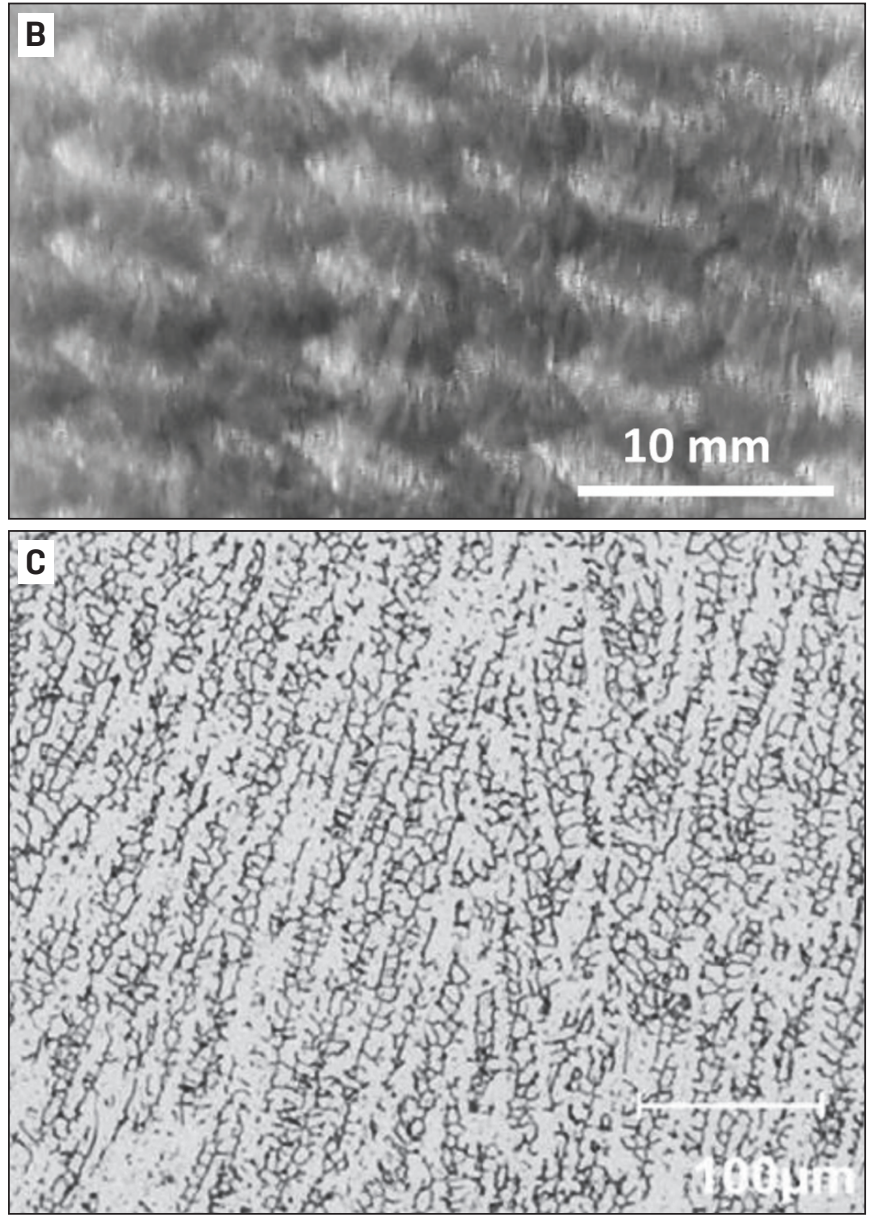

of weld, as summarized in Table 2. The LAM-W part was made at a travel speed of $1.2 \mathrm{~m} / \mathrm{min}$, which is $3.8 \times$ faster than the WAAM part, and $4.8 \times$ faster than the EBAM-W part. Increasing travel speed influences the weld by reducing the overall size of the weld pool, elongating the weld pool length relative to its width, lowering the heat input per unit length of weld for a given power while increasing the cooling rate of the weld, and refining the microstructure (Ref. 23). When factoring in both the weld power and speed, the heat input per unit length was the lowest for LAM-W at $70 \mathrm{~J} / \mathrm{mm}$, while the WAAM was $5.3 \times$ higher, and EBAM-W was $10.7 \times$ that of the laser process. Based on this parameter alone, one would expect the LAM-W would be quite different than the other two processes, and the

Table 3 - Summary of Dendrite Arm Spacing (DAS) and Estimated Cooling Rates for Each of the Three Processes. The Cooling Rate and DAS Ranges Occur Within an Individual Weld Bead

Process

Feature

LAM-W

WAAM

EBAM-W
Primary DAS

Secondary DAS

Primary DAS

Secondary DAS

Primary DAS

Secondary DAS
DAS Constants for Eq. 1

(C/n)

$80 / 0.33$

$25 / 0.28$

$80 / 0.33$

$25 / 0.28$

$80 / 0.33$

$25 / 0.28$
Spacing Range

$(\mu \mathrm{m})$

6-8

3-4

19-25

7-9

20-26

8-10
Cooling Rate Range

$(\mathrm{K} / \mathrm{s})$

1070-2560

695-1940

34-78

38-94

30-66

26-58 


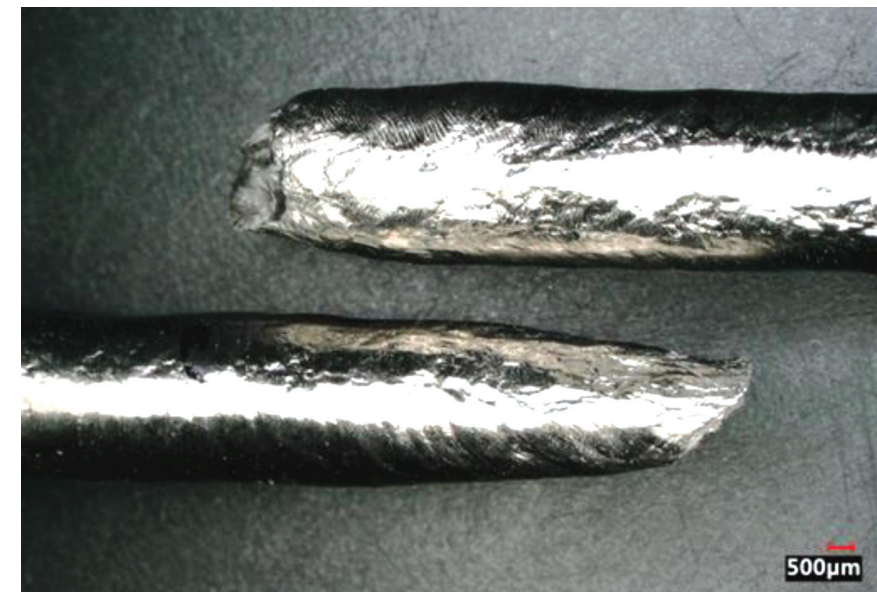

Fig. 9-Photograph of a failed WAAM tensile bar showing the effects of large grains creating a dimpled surface in the gauge length and at the necked region on the sample.

WAAM and EBAM-W would be closer to each other. This appears to be true for the macrostructural features shown in Figs. 5A, B; 8A, B; and 11A, B for laser, arc, and electron beam, respectively. In these figures, it is clear the laser produced the smallest weld pool sizes and most refined microstructures.

The approximate weld pool cross-section sizes were measured and summarized in Table 2, which shows the large difference between the laser welds and the other two processes. The semicircular LAM-W weld pool measured approximately $3 \mathrm{~mm}$ wide and $1.0 \mathrm{~mm}$ deep with a crosssectional area of approximately $2.5 \mathrm{~mm}^{2}$. The WAAM weld pool measured approximately $9 \mathrm{~mm}$ wide by $4.5 \mathrm{~mm}$ deep with a cross-sectional area of approximately $25 \mathrm{~mm}^{2}$. The weld pool had a deeper penetrating center region at the root of the weld, and it was shallower near the weld toe than the laser weld. This weld cross section is sometimes referred to as finger penetration. The nearly semicircular EBAM-W weld pool measured approximately $10 \mathrm{~mm}$ wide by $6 \mathrm{~mm}$ deep and had a cross-sectional area of approximately $45 \mathrm{~mm}^{2}$, with slightly deeper penetration than a semicircular shape. In all cases, these weld pool shapes were overlapped approximately $50 \%$ and penetrated approximately $50 \%$ of the weld width into the previous layer.

The microstructures at high magnification are shown in Figs. 5C, 8C, and $11 \mathrm{C}$ for laser, arc and electron beam, respectively. Note the difference in magnifications used in these micrographs, where the laser is shown at higher magnification to bring out details of its finer structure. The microstructures are typical of welded 308L SS, where the dendritic nature of solidification is clearly seen by the presence of the dark etching residual delta ferrite phase (Refs. 23, 24). The residual ferrite in the microstructure formed from ferrite dendrites solidifying as the primary phase with fully developed secondary arms for all three processes. The spacing of the primary and secondary arms is related to the cooling rate during solidification, where higher solidification rates produce smaller DAS sizes. The relationship between the microstructure scale and cooling rate during welding is represented by the following equation (Refs. 23-25):

$$
\lambda=c(\varepsilon)^{-n}
$$

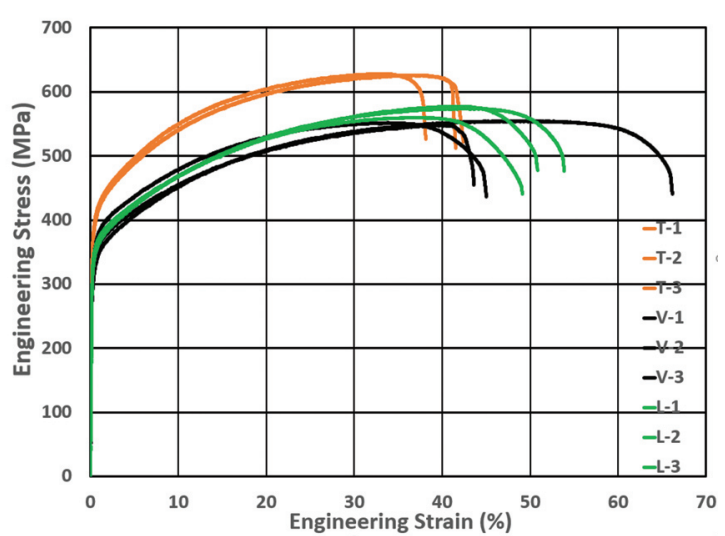

Fig. 10 - WAAM tensile results for the three orientations, showing the transverse direction $(T)$ to have the highest yield and ultimate strength.

In this equation, $\lambda$ represents the DAS in microns, $\varepsilon$ is the cooling rate during solidification in $\mathrm{K} / \mathrm{s}, \mathrm{C}$ is a constant, and $\mathrm{n}$ is the cooling-rate exponent that can be found from the slope of a cooling rate vs. microstructural scale plot. The constants $C$ and $\mathrm{n}$ are different for primary and secondary dendrite arms, and these constants are summarized in Table 3 using data from the literature for SS alloys of similar composition (Ref. 24). Table 3 also summarizes the primary and secondary DAS measurements for each of the processes. From these measurements, the estimated cooling rate range was calculated using Equation 1. Note that a range of DAS measurements is given that is observed in a single bead, where smaller spacings tend to appear on the bottom of the bead, and larger spacings appeared toward the top.

These results show LAM-W had the most refined microstructure with a primary DAS range of 6-8 microns and a secondary DAS range of 2.5-4 microns, which corresponds to a range of cooling rates from approximately 1000 to $2000 \mathrm{~K} / \mathrm{s}$ depending on the measurement and location. Wire arc AM had a coarser microstructure with a primary DAS range of 18-25 microns and a secondary DAS range of 7-9 microns, which corresponds to cooling rates less than $100 \mathrm{~K} / \mathrm{s}$, i.e., more than one order of magnitude lower than LAM-W. Wire-fed electron beam AM had an even coarser microstructure with a primary DAS range of 20-26 microns and a secondary DAS range of 8-10 micron, which produced cooling rates less than that of WAAM and on the order of $50 \mathrm{~K} / \mathrm{s}$, depending on measurement and location.

In addition to affecting the DAS and cooling rates, the different processes also had different ferrite contents, hardness values, and oxygen contents as summarized in Table 2. A complete chemical analysis for the samples, shown in Table 1, reveals that the composition of all of the builds were close to the composition of the welding wire, except for the oxygen content, which was elevated approximately $6 \times$ relative to the starting welding wire for the WAAM and LAM-W processes, and would be considered to be out of specification for most applications (Ref. 9). Oxygen contents for the three wire-based builds show that only the EBAM-W had the same level of oxygen as the welding wire due to the superior vacuum conditions for this process, which is a big 


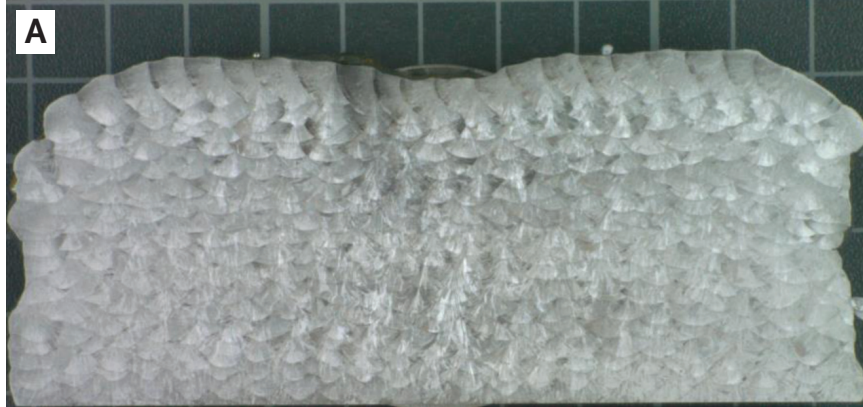

Fig. 11 - EBAM-W microstructures: A - Photograph of the polished and etched $110-\mathrm{mm}$-wide brick cross section with 1-cm background markings; $B$ - photograph of the weld bead and grain structure detail; $\mathrm{C}$ - residual delta ferrite microstructure at high magnification.

advantage of this process, particularly for refractory and other metals that are sensitive to oxygen or nitrogen pickup from the atmosphere.

The residual ferrite content of the weld is related to its composition, specifically $\mathrm{Cr} / \mathrm{Ni}$ equivalent ratio, and the cooling rate of the weld. Higher $\mathrm{Cr} / \mathrm{Ni}$ ratios solidify with higher delta ferrite contents, and higher cooling rates tend to retain more of the delta ferrite because there is less time for solidstate transformation of ferrite to austenite as the weld cools to room temperature (Refs. 23, 24, 26). Although all of the processes used 308L SS welding wire, they were of slightly different compositions, as summarized in Table 1, and had different $\mathrm{Cr} / \mathrm{Ni}$ ratios, as calculated using the Suutala equivalents (Ref. 27) as follows: $\mathrm{Cr}_{\mathrm{eq}}=\mathrm{Cr}+1.37 \mathrm{Mo}+1.5 \mathrm{Si}+2 \mathrm{Nb}+3 \mathrm{Ti}$ and $\mathrm{Ni}_{\text {eq }}=\mathrm{Ni}+0.31 \mathrm{Mn}+22 \mathrm{C}+14.2 \mathrm{~N}+\mathrm{Cu}$. The calculated $\mathrm{Cr} / \mathrm{Ni}$ ratios of the welding wire were 1.83 for LAM-W, 1.75 for WAAM, and 1.73 for EBAM-W. The residual ferrite contents of the three builds were 9.1 FN for LAM-W, 7.7 FN for WAAM, and 4.9 FN for EBAM-W. 308L SS weld compositions are designed to retain approximately $8 \mathrm{FN}$ ferrite to prevent solidification cracking during typical arc welding conditions, which is what was observed for the WAAM sample that had 7.7 FN. The LAM-W sample had a higher ferrite content of $9.1 \mathrm{FN}$, which is likely the result of both its higher $\mathrm{Cr} / \mathrm{Ni}$ ratio and its higher cooling rate. The EBAM-W sample had a lower than typical ferrite content for 308L SS of $4.9 \mathrm{FN}$, which is most likely due to its slower cooling rate and subsequent phase transformations after solidification because its $\mathrm{Cr} / \mathrm{Ni}$ ratio is typical for 308L SS. It is important to note all of the samples showed primary ferrite solidification with no solidification cracking on the surface of the bricks or in microstructures observed in the cross sections.

\section{Mechanical Behavior}

The hardness values of the three different processes trended inversely with the heat input per unit length where the LAM-W sample had the highest hardness and the EBAM-W had the lowest hardness, as summarized in Table 2. The macrohardness values ranged from 83.1 HRB for EBAM-W to 92.5 HRB for LAM-W, while the microhardness values ranged from 172.6 HV for EBAM-W to $214 \mathrm{HV}$ for LAM-W. These trends in hardness were expected as a result of differing heat input on multiple factors, including the scale of the mi-
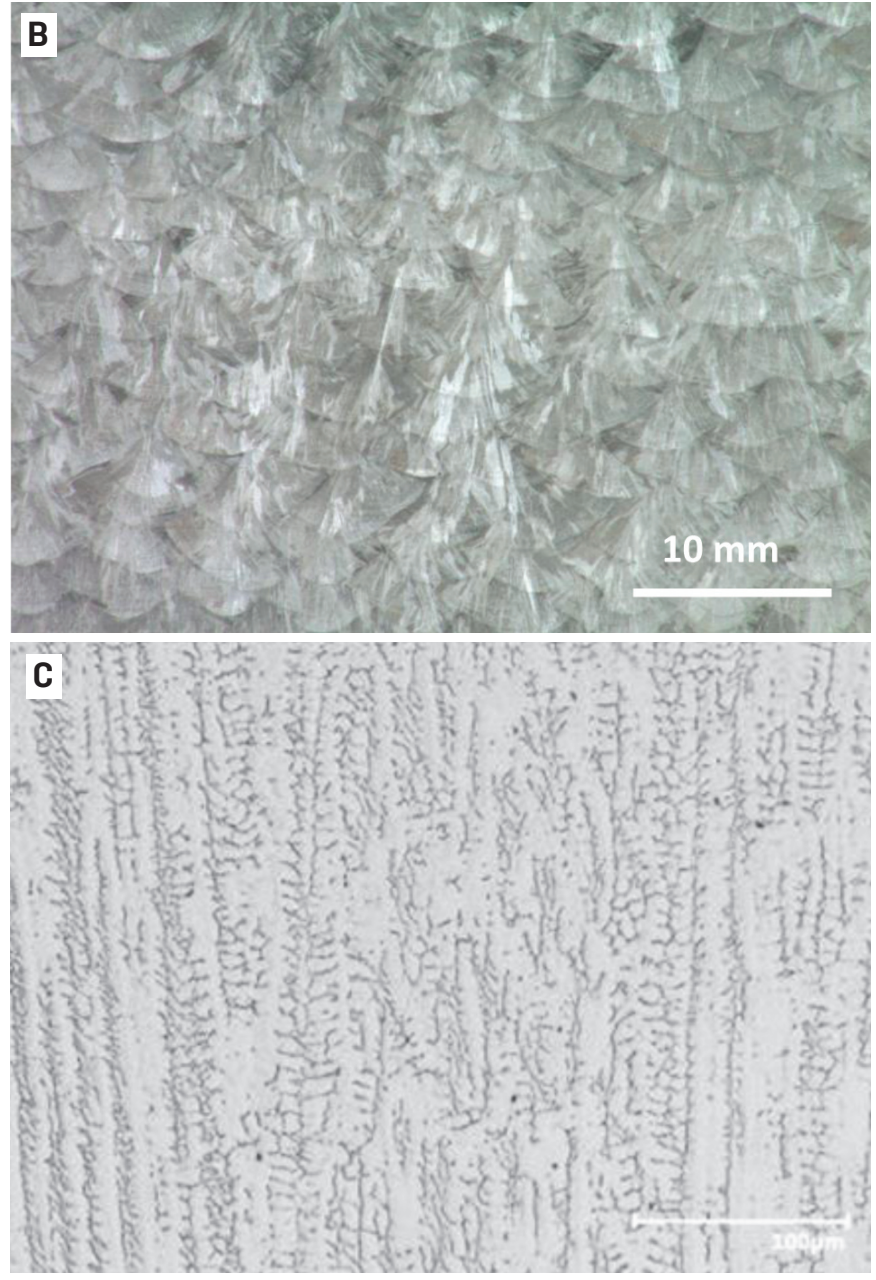

crostructure, size of the columnar grains, presence of oxide inclusions, amount of delta ferrite, and annealing that occurs more during the higher heat input welds. These effects will also influence other mechanical properties such as strength, ductility, and toughness. The tensile properties of the bricks were measured in three different orientations relative to the build for each of the processes, and the results are summarized in Table 2 for yield and ultimate strengths, elongation to failure, and modulus of elasticity. The data are further shown in Fig. 14, which plots the four properties individually for each process and each orientation.

The yield strengths for each process are compared in Fig. $14 \mathrm{~A}$ where the strength follows the same trend as the hardness for all orientations, with LAM-W having the highest strength and EBAM-W having the lowest strength. The yield strength had a large range from 283 to $482 \mathrm{MPa}$, but all orientations and processes exceeded the minimum yield strength of annealed 304L SS of $172 \mathrm{MPa}$, and in the case of LAM-W it was $2.8 \times$ higher.

The ultimate tensile strengths for each process are compared in Fig. 14B, showing similar trends as the yield strength where LAM-W in the T orientation had the highest strength and EBAM-W in the L orientation had the lowest strength. The range of ultimate strengths varied from 528 to $658 \mathrm{MPa}$, which is smaller than the range of yield strengths. All of the orientations and processes exceeded the minimum ultimate strength of annealed 304L SS of 483 


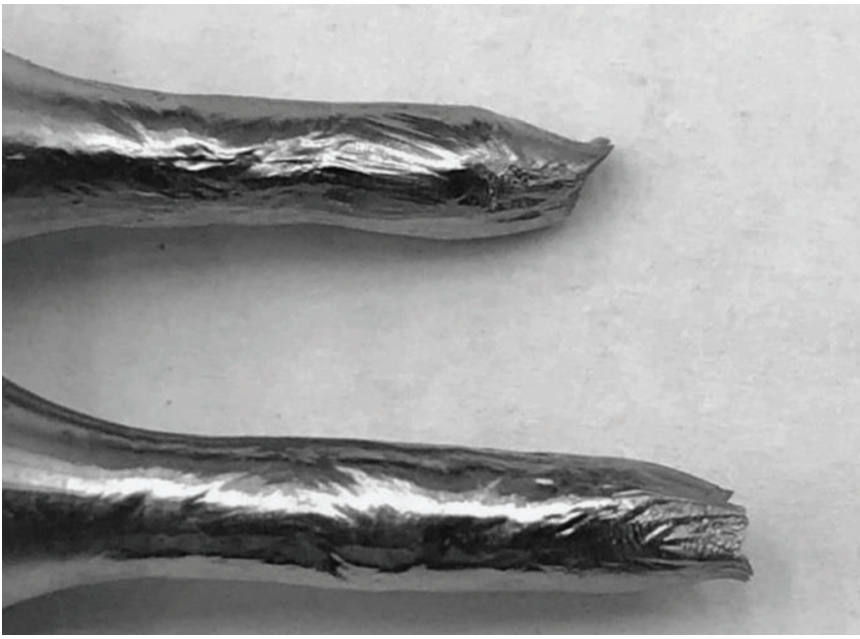

Fig. 12 - Photograph of a failed EBAM-W tensile bar showing the effects of large grains creating a lumpy surface throughout the entire gauge length.

$\mathrm{MPa}$, and in the case of LAM-W in the transverse orientation, which was $1.7 \times$ higher. The elongation to failure for each process that did not seem to follow a strong trend are plotted in Fig. 14C. The lowest values tended to be for the $\mathrm{T}$ orientation and varied from $41.7 \%$ (WAAM, T) to $51.9 \%$ (WAAM, L). All elongations exceeded the minimum for annealed 304L SS of $40 \%$.

Figure 14D compares the modulus of elasticity for all orientations and processes, which had a very large range from 133.1 to $220.6 \mathrm{GPa}$. This range of moduli spans the typical value reported for polycrystalline annealed 304 SS of 193 $\mathrm{GPa}$ as the result of texture, and is very similar to that observed in selective laser melting of 316 SS (Ref. 28), which is created during AM.

Figure 15 shows close-up photographs of the necked regions of the failed tensile bars from the WAAM brick for the transverse, longitudinal, and vertical orientations. In terms of strength and ductility, the transverse orientation had the highest average yield strength of $382 \mathrm{MPa}$ and the lowest average elongation of $41.7 \%$, whereas the other two orientations had elongations significantly higher at 51.6 and $51.9 \%$. The visual appearance of the T and L samples were similar, both being in the same plane that is parallel with the build layer planes, but at a 90-deg rotation from each other. The T-oriented sample appeared to have larger facets than the L-oriented sample, and it did not neck down as much. The T-oriented sample failed at an approximate 45deg angle across its face, whereas the L-oriented sample failed in a cup and cone manner. The V-oriented sample had a different appearance with the grains clearly elongating along the tensile axis, where elongated ridges formed on the surface of the bar parallel to the tensile axis. The ridges curved to become more parallel with the tensile axis closer to the broken end where some necking was observed. It is believed the V-oriented sample showed the effects of the columnar grains, which tend to grow in the vertical direction through multiple layers, as observed in the macrophotograph of the WAAM brick cross section in Fig. 8A.

All of the tensile bar orientations showed slip bands that appeared to lie in planes largely perpendicular to the tensile

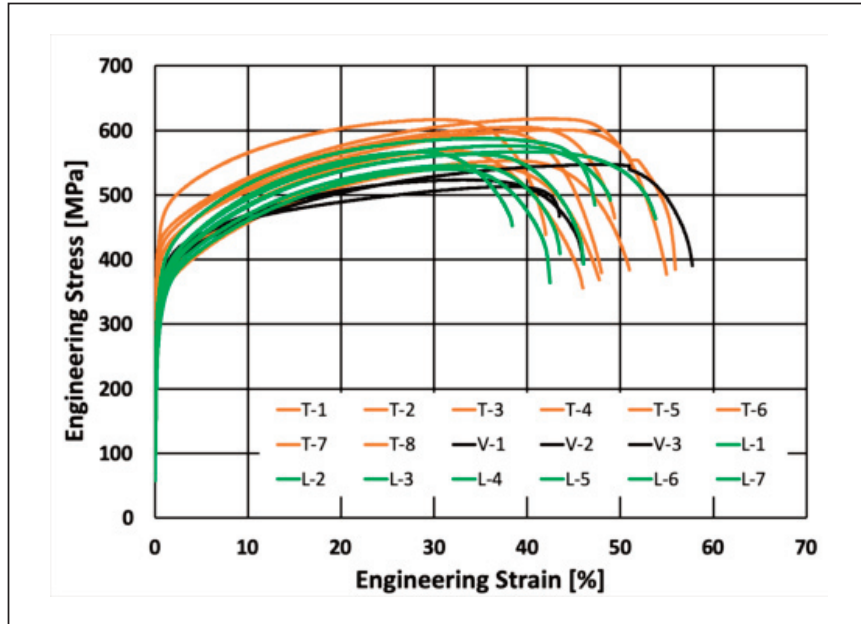

Fig. 13 - EBAM-W tensile test results for the transverse (I), longitudinal (L), and vertical ( $V$ ) orientations.

axis. The band spacing was on the order of 100 microns with finer spacings on average observed in the V-orientation. Figure $16 \mathrm{~A}$ shows a cross section through the center of one half of a broken tensile bar to illustrate the inhomogeneous deformation that occurs. This sample is from a longitudinal orientation and contains approximately $10 \mathrm{~mm}$ of a tapered region leading to the neck and final failure of the sample. The wavy surface is evidence of grains deforming at different rates, which can be seen more clearly in Fig. 16B with a higher magnification of the fractured end. Slip bands that intersect the surface of the tensile bar are shown in Fig. 16C in a region that etches darker than the surrounding areas, indicating higher localized deformation in the slip-band region. Additional future work is planned to perform electron backscatter diffraction studies and characterize the grain orientations in the necked region of the tensile samples.

\section{Texture and Anisotropy}

The mechanical property data shows that all three processes produce properties that meet or exceed the minimum requirements for annealed 304L SS, which is the wrought equivalent of 308L SS, but there are significant differences in the properties depending on the process and sample orientation. It is well known that the elastic modulus, and other properties such as yield strength and thermal expansion, of a single crystal depends on its crystallographic orientation for metals and alloys, such as SS that are elastically anisotropic (Refs. 28-31). These differences can be significant, and in the case of modulus, elastic anisotropy is known to vary by more than $3 \times$ for single-crystal SS alloys (Refs. 29, 30). Calculations (Ref. 32) using elastic constants from Ledbetter (Ref. 29) showed the elastic modulus for austenitic SS such as 308L will have the lowest value of 94 $\mathrm{GPa}$ in the [100] direction, an average value of $193 \mathrm{GPa}$, which would be expected in the [110] direction, and the highest value of $299 \mathrm{GPa}$ in the [111] direction. In a polycrystalline sample, this effect will not be as extreme, but can still vary considerably depending on the size of the grains and their degree of randomness. If the grains in the metal are randomly oriented in a large sample composed of many 
A

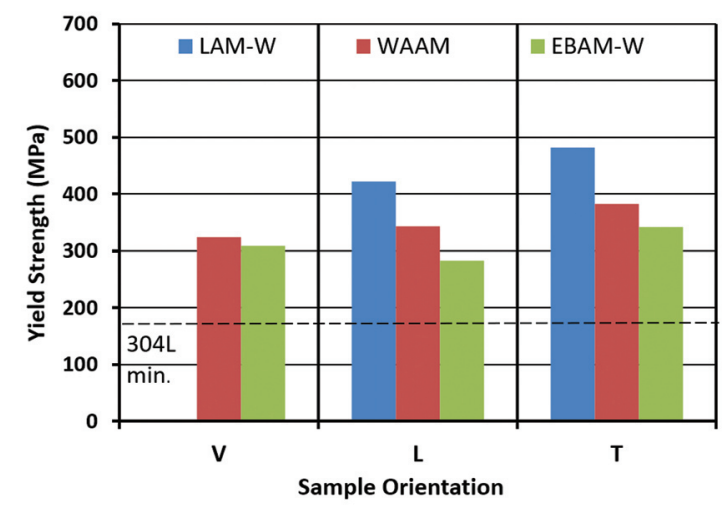

C

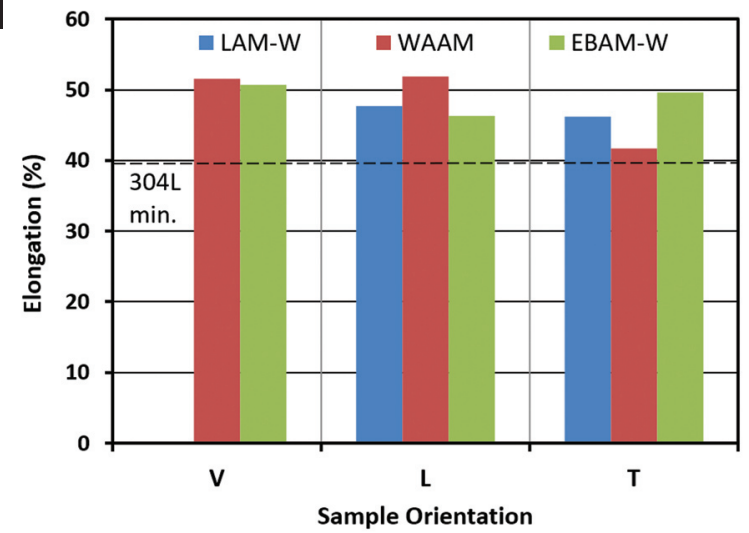

B

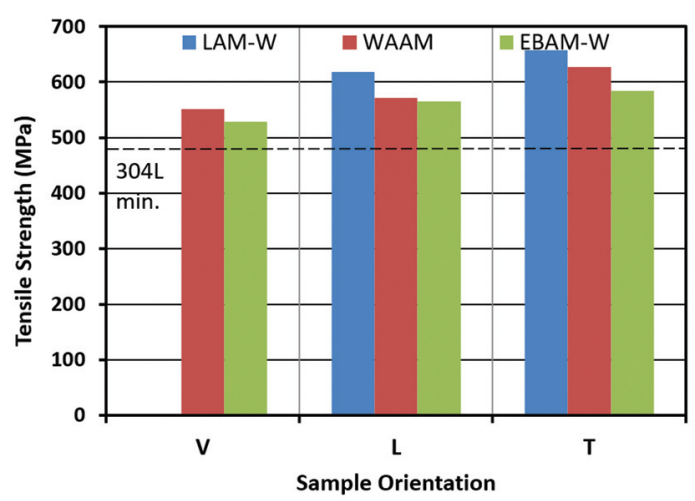

D

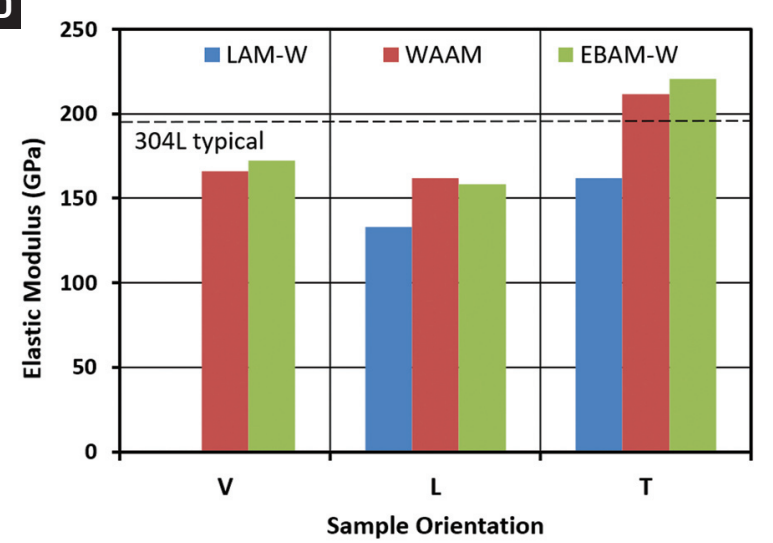

Fig. 14 - Summary of the mechanical property tests for each AM process as a function of sample orientation. The horizontal dashed lines correspond to properties of annealed 304L SS.

grains, the sample may appear to be isotropic as the crystallographic effects are averaged out. However if the grains are large and nonrandom, i.e., textured, then the properties will be in different orientations.

Figure 14D shows that sample orientation plays a role in the modulus of elasticity of the 308L SS wire-fed AM builds for all three wire-fed AM processes. The highest values were more than $210 \mathrm{GPa}$ in the transverse direction for WAAM and EBAM, while lower values were on the order of $160 \mathrm{GPa}$ for the other orientations, with the lowest values being for the LAM-W of $133.1 \mathrm{GPa}$ in the L orientation. When compared to wrought 304L SS, the 308L SS AM bricks made

Table 4- Qualitative Comparison of the Three Wire-Based AM Processes

Property

Cost of equipment

Cost of operation

Deposition rate

Weld pool size

Surface finish

Weld speed

Energy/unit length

Energy $/ \mathrm{kg}$ deposited

Dendrite spacing

Cooling rate

Yield strength

Ultimate strength

Hardness

Elongation

Atmosphere control

Oxygen pickup

Grain texture effects
LAM-W

WAAM

EBAM-W

L

$\mathrm{H}$

$\mathrm{H}$

L

M

L

$\mathrm{H}$

$\mathrm{H}$

$\mathrm{H}$

M

L

$\mathrm{H}$

M

$L$
$L$
$H$
$M$
$M$
$M$
$M$
$L$
$M$
$M$
$M$
$M$
$M$
$M$
$L$
$H$
$H$

$H$
$H$
$M$
$H$
L
L
$H$
$H$
$H$
L
L
L
L
M
$H$
L
$H$ 


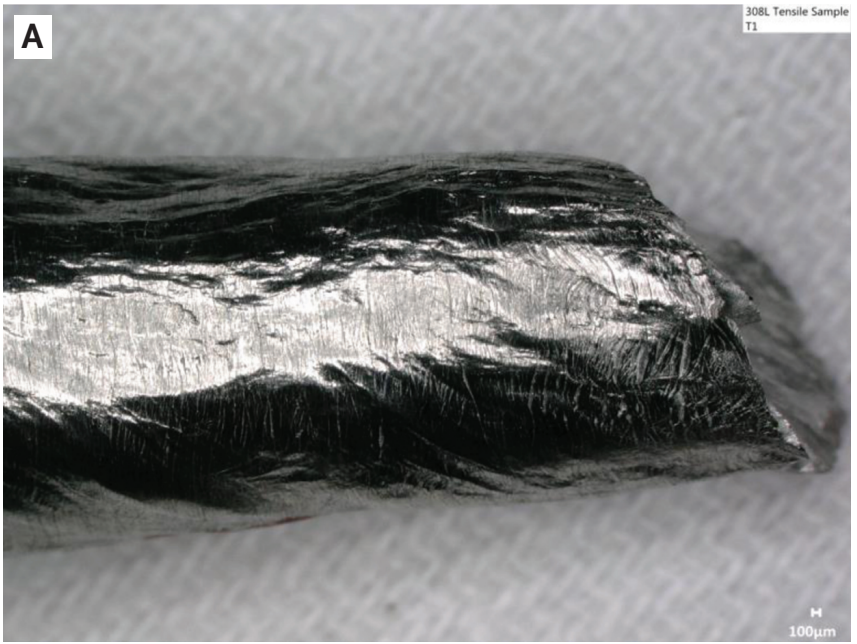

Fig. 15 - Comparison of the necked regions of the failed tensile bars from the WAAM brick: A - Transverse direction; $B$ - longitudinal direction; $C$ - vertical orientations.

from all three processes were clearly textured. The texture is related to the elongated columnar grains that form during solidification and tend to follow the [100] crystallographic direction (Ref. 33). These grains curve and spiral into the weld pool as it solidifies depending on the weld pool shape (Refs. 34-36). They are also not oriented parallel to any one of the three principal directions of the brick (i.e., T, V, or L). In addition, epitaxial growth from multiple overlapping passes during a 3D build creates grain patterns that would not normally exist in single-pass welds. Tensile bars removed from these complex microstructures have orientations that contain off-columnar axis components, which results in variations in the elastic modulus and in the mechanical properties different than the [100] direction.

The elastic modulus values for all of the wire-based AM processes averaged $173 \mathrm{GPa}$, which is about $10 \%$ less than that of typical annealed wrought base metal. In all three processes, the transverse orientation had a higher modulus than the other two orientations, and was higher than that of annealed wrought base metal SS by a considerable amount for the WAAM and EBAM-W processes. Based on the elastic modulus measurements, it might be expected that the transverse orientation contained more grains closer to the [111] direction, and the other two orientations contained grains closer to the [100] direction to give the measured range of modulus values observed. This can partially be explained in a qualitative sense by thinking about the overlapping weld beads that make up the AM bricks. Cross sections for each of the wire-fed bricks were shown in previous figures in the $\mathrm{T}-\mathrm{V}$ plane, i.e., perpendicular to the welding direction, showing arc-shaped remnants of previous weld beads that were partially remelted as new layers are added to the build. The arc shapes were present in a regular array created by the repeated parallel weld beads, and generated a macroscopic pattern that was also related to the grain texture. It is interesting to note that even though LAM-W, WAAM, and EBAM-W are all made with different heat inputs per unit length and weld pool sizes, all three processes showed the transverse direction as having a higher elastic modulus. However, the LAM-W process had lower modulus values than the other two, with both the $\mathrm{L}$ and $\mathrm{T}$ orientations being less
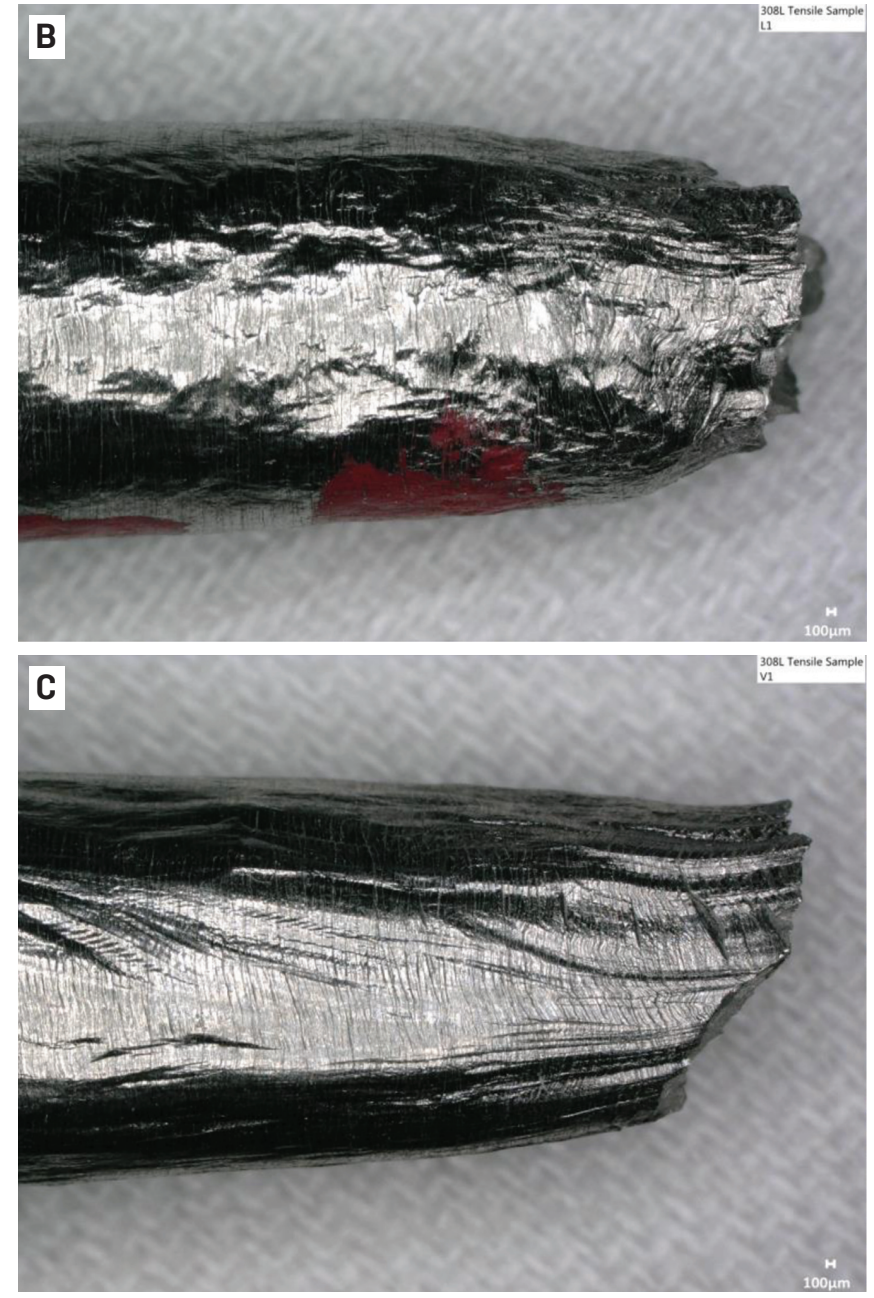

than annealed polycrystalline 304 SS base metal.

Figure 17 shows a schematic representation of the overlapping weld pools in an AM build to indicate how the macrostructure develops. The red highlighted region represents the portion of a weld bead that does not get remelted by subsequent passes, providing the substrate for other passes to solidify from and leaving the bottom portion of the weld fusion line intact. Lines drawn in the weld beads indicate the general direction of heat flow and how, in this case, three different overlapping grains epitaxially grew from the one red highlighted bead. The orientation of dendrites and grains in the previous layer will intersect those growing along the heat flow direction of the new weld pool at different angles depending on where the weld pools overlap. New dendrites and grains will grow epitaxially from the existing dendrites and grains, and will attempt to orient themselves to the new heat flow direction, creating texture in the AM build. Although the $3 \mathrm{D}$ curved path the grains follow in welds cannot be represented in the two-dimensional (2D) cross section shown above, these views can be helpful to visualize how texture develops in the multipass AM builds.

In other studies, the grain texture had been calculated in the fusion zone of single-weld beads using a Monte Carlo code and coupled thermal fluids modeling. This model illustrates how dendrites and grains follow a curved path as they grow along the maximum thermal gradient in a solidifying weld pool, using a simplified 2D model of weld solidification (Ref. 


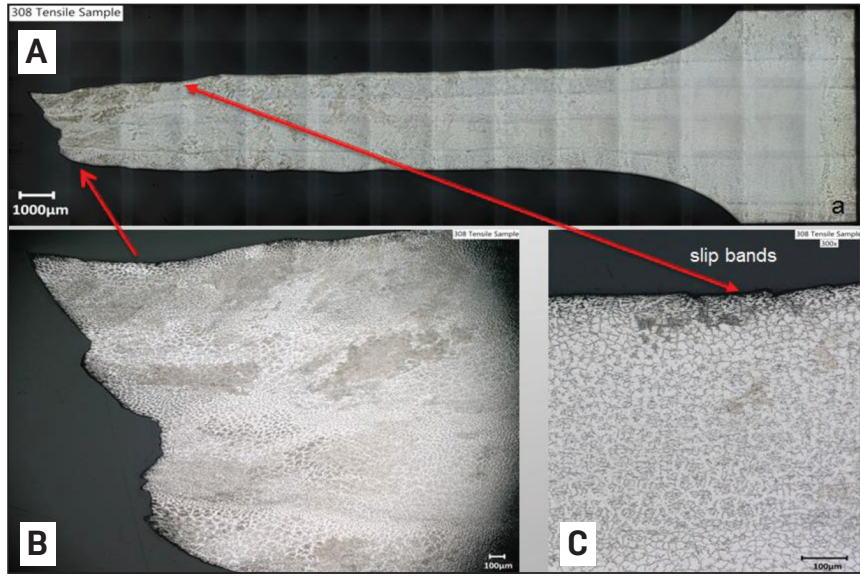

Fig. $16-A-$ Cross section through the center of a broken tensile bar; $B$ - higher magnification detail near the fracture surface; $C$ - higher magnification detail in the necked portion of the gauge length.

34) and a full 3D model of weld solidification (Refs. 35, 36). The path the grains follow is a direct result of the weld pool shape and doesn't lie in a single plane except along the centerline of the weld. Therefore, none of the three principal orientations of the tensile bars will be composed of a single given crystallographic orientation. They will show some degree of texture depending upon how the [100] grains intersect the tensile axis.

\section{Qualitative Comparison of the Three Wire-Fed Processes}

The three processes each have advantages and disadvantages related to cost, ease of operation, microstructures that are produced, deposition rates, surface finish, and mechanical properties. These aspects are important considerations when deciding on which process to use or invest in, and are highly specific to the final part being produced. Table 2 presented a detailed comparison of the processing parameters for each process and the results obtained. It indicates LAM$W$ was made with the least energy per unit length, WAAM had an intermediate energy per unit length of weld of approximately $5 \times$ that of the laser process, and EBAM-W had the highest energy per unit length of weld at approximately $10 \times$ that of the laser process.

Many of the comparisons between the processes link back to the heat input factors in different ways. Table 4 presents a qualitative comparison of the three processes, where the different factors based on the results of this study are indicated as low, L; medium, M; or high, $\mathrm{H}$. This comparison is useful when considering tradeoffs for each process. For example, if one needs a part fabricated at high deposition rates where surface finish is a priority, then LAM-W would be a good choice based on its finer bead size and weld pool control. If cost per $\mathrm{kg}$ of material deposited is more important, then WAAM would be a good choice based on its high deposition rate, low operating and capital equipment cost, and low amount of energy per kg deposited. If chemical control of the final part is important and/or the part is being manufactured from reactive metals, then EBAM would

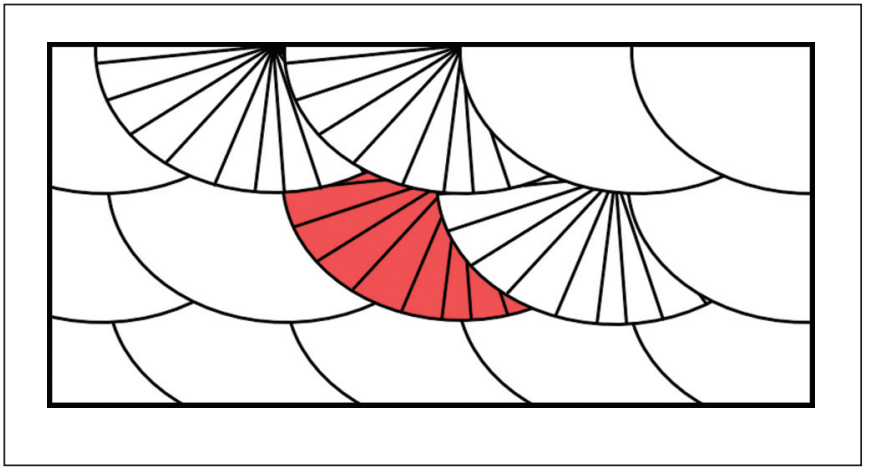

Fig. 17 - Schematic representation of overlapping weld pools in an AM build. The red highlighted region represents the portion of a weld bead that does not get remelted by subsequent passes, providing the substrate for other passes to solidify from.

be the best choice based on the vacuum environment, which eliminates the possibility of picking up unwanted contamination from the atmosphere.

In terms of mechanical properties of 308L SS, all processes produced properties that, when compared to annealed 304L SS, showed very favorable results. In all cases, the yield strength, tensile strength, and hardness exceeded that of annealed 304L SS, but there was a clear ranking. The LAM$W$ process had the highest strengths and EBAM-W had the lowest, which was largely the result of reduced heat input into the part and the more refined microstructure that it produces. The tensile ductility was not as sensitive to the process; however, there were mixed results depending on tensile sample orientation, such that all of the processes had reasonable ductility that exceeded the minimum for annealed 304 SS. This is a somewhat remarkable result in that the LAM-W process produced the strongest parts with no obvious loss in ductility compared to the other processes. Because of this, LAM-W would be a good choice if increased strength is an important design factor. In terms of texture and the resulting anisotropic properties, all three processes showed a significantly high degree of texture based on microstructural observations, elastic moduli, and orientationdependent tensile strength properties. For each of the processes, the transverse tensile orientation had comparatively higher strengths than the other two orientations, which is a direct result of the solidification grain structure that forms during the layer-by-layer build.

\section{Conclusions}

In summary, the mechanical properties and microstructure of 308L SS parts made by three different wire-based AM technologies were measured, and the following conclusions were made:

1) Best practice build parameters were developed for each wire-based AM process, resulting in significant differences between them. Wire-fed laser AM used the highest speed, had the smallest weld pool, and had the lowest heat input per unit length of weld. Wire arc AM used a medium speed, had a medium-sized weld pool, and had $5 \times$ the energy per length as the laser process. Wire-fed electron beam AM used 
the lowest speed, had the largest weld pool, and had the highest energy per unit length of approximately $10 \times$ that of the laser process. However, when wire-feed rate was factored in, the energy per $\mathrm{kg}$ of metal deposited only varied by $2.5 \times$ between the three processes, with WAAM being the most efficient and EBAM-W being the least efficient.

2) The differences in heat input between the three processes resulted in differences in the microstructure. Wire-fed laser AM had the most refined microstructure as a result of its higher cooling rate during solidification, which was estimated to be on the order of $1000 \mathrm{~K} / \mathrm{s}$ based on DAS measurements. Comparatively, WAAM and EBAM-W had less refined microstructures as a result of their slower cooling rates during solidification, which were estimated to be less than $100 \mathrm{~K} / \mathrm{s}$ based on DAS measurements, with EBAM$\mathrm{W}$ having the lowest cooling rates of the three processes.

3) Residual delta ferrite in the microstructure showed significant differences between the three processes. Wirefed laser AM and WAAM had the highest ferrite contents of 9.1 FN and 7.7 FN, respectively, which is typical for 308L SS welds. Wire-fed electron beam AM had a ferrite content of $4.9 \mathrm{FN}$, which was lower than expected for 308L SS. Since all three procesess solidified in the primary ferrite mode based on microstructural observations, the low ferrite content of EBAM-W was most likely due to its slow cooling rate through the ferrite to austenite solid-state transformation temperature range because typical electron beam single-pass welds would not show a reduced ferrite content.

4) The composition of the parts built by each process was very similar to the starting wire composition except for the oxygen content. Wire-fed laser AM and WAAM both picked up significant oxygen of $6 \times$ or greater than the wire composition. On the other hand, wire-fed electron beam AM showed no pickup of oxygen due to its superior vacuum conditions that are maintained during the build. Although the oxygen pickup by LAM-W and WAAM did not appear to adversely affect the mechanical properties of 308L SS, it is important to note that this could be a concern when building parts out of oxygen-sensitive metals or alloys.

5) The mechanical properties of the parts all exceeded the minimum values of annealed wrought 304L SS; however, there were differences between the three processes. Wirefed laser AM had the highest ultimate strength, yield strength, and hardness value, whereas EBAM-W had the lowest strength and hardness. These factors are a direct result of heat input and its effects on microstructure. Although the strengths were process dependent, the elongation to failure did not show any significant differences between the three processes.

6) Microstructural texture was observed in all of the parts as a result of the elongated columnar grains that form during solidification, combined with epitaxial growth from one layer to the next. The texture resulted in anisotropic properties in strength and elastic modulus. For a given process, the transverse orientation showed the highest strength and highest modulus, while the other two orientations, vertical and longitudinal, had properties similar to each other.

7) A comparison of the three processes showed relative advantages of each depending on the final application. For the parameters developed here, LAM-W demonstrated the best weld pool control and highest strength, making it use- ful when surface finish and mechanical properties are important. Wire arc AM was the lowest cost process that produced the highest deposition rates with good resulting properties and surface finish, making it advantageous for larger parts. Wire-fed electron beam AM demonstrated the best control of the composition by preventing pickup of oxygen, making it useful for building parts out of atmospheresensitive alloys.

\section{Acknowledgments}

The authors with Lawrence Livermore National Laboratory would like to thank John Sengthay, Cheryl Evans, and James Embree for metallography and hardness testing; Dave Urabe and Victor Hepa for tensile testing; and Dr. Jeff Florando for assistance with elastic modulus calculations. The authors with Aldermaston Weapons Establishment would like to thank Laserline GmBH (Fraunhofer Straße 56218 Mülheim-Kärlich/Germany) for making the LAM-W 308L SS component used in this investigation. The authors would also like to thank the people who helped with LANL EBAM research, development, and operations: Andy Duffield for Sciaky EBAM operation; Barry Bingham and Ruth Ann Vargas for procurement support; J. J. O'Connor for the facility; Jeff Vigil and Jeff Robinson for machining of the tensile and metallography samples; and J. D. Montalvo and Eric Tegtmeier for metallography sample preparation and micrographs.

\section{Auspices and Disclaimer}

The Lawrence Livermore National Laboratory portion of this work was performed under the auspices of the U.S. Department of Energy by Lawrence Livermore National Laboratory under Contract DE-AC52-07NA27344. This document was prepared as an account of work sponsored by an agency of the U.S. government. Neither the U.S. government, Lawrence Livermore National Security LLC, nor any of their employees make any warranty, expressed or implied, or assume any legal liability or responsibility for the accuracy, completeness, or usefulness of any information, apparatus, product, or process disclosed, or represent that its use would not infringe privately owned rights. Reference herein to any specific commercial product, process, or service by trade name, trademark, manufacturer, or otherwise does not necessarily constitute or imply its endorsement, recommendation, or favoring by the U.S. government or Lawrence Livermore National Security LLC. The views and opinions of authors expressed herein do not necessarily state or reflect those of the U.S. government or Lawrence Livermore National Security LLC, and shall not be used for advertising or product endorsement purposes.

\section{References}

1. DebRoy, T., et al. 2018. Additive manufacturing of metallic components - Process, structure and properties. Progress in Materials Science 92: 112-224. DOI: 10.1016/j.pmatsci.2017.10.001

2. Sames, W. J., List, F. A., Pannala, S., Dehoff, R. R., and Babu, S. S. 2016. The metallurgy and processing science of metal additive 
manufacturing. International Materials Reviews 61(5): 315-360. DOI: 10.1080/09506608.2015.1116649

3. Milewski, J. O. 2017. Additive Manufacturing of Metals: From Fundamental Technology to Rocket Nozzles, Medical Implants, and Custom Jewelry. Springer International Publishing.

4. Ding, D., Pan, Z., Cuiuri, D., and Li, H. 2015. Wire-feed additive manufacturing of metal components: Technologies, developments and future interests. The International Journal of Advanced Manufacturing Technology 81(1-4): 465-481. DOI: 10.1007/ s00170-015-7077-3

5. DebRoy, T., et al. 2019. Scientific, technological and economic issues in metal printing and their solutions. Nature Materials 18: 1026-1032. DOI: 10.1038/s41563-019-0408-2

6. EBAM ${ }^{\circledR}$ is a trademark of Sciaky Inc., Chicago, Ill.

7. Block-Bolten, A., and Eagar, T. W. 1984. Metal vaporization from weld pools. Metallurgical Transactions B 15(3): 461-469. DOI: 10.1007/bf02657376

8. Bermingham, M. J., Thomson-Larkins, J., St. John, D. H., and Dargusch, M. S. 2018. Sensitivity of Ti-6Al-4V components to oxidation during out of chamber wire + arc additive manufacturing. Journal of Materials Processing Technology 258: 29-37. DOI: 10.1016/j.jmatprotec.2018.03.014

9. Elmer, J. W., and Gibbs, G. 2019. The effect of atmosphere on the composition of wire arc additive manufactured metal components. Science and Technology of Welding and Joining. Special Issue on Additive Manufacturing and 3D Printing 24(5): 367-374. DOI: 10.1080/13621718.2019.1605473

10. Demir, A. G. 2018. Micro laser metal wire deposition for additive manufacturing of thin-walled structures. Optics and Lasers in Engineering 100: 9-17. DOI: 10.1016/j.optlaseng.2017.07.003

11. Baufeld, B., Brandl, E., and van der Biest, O. 2011. Wire based additive layer manufacturing: Comparison of microstructure and mechanical properties of Ti-6Al-4V components fabricated by laserbeam deposition and shaped metal deposition. Journal of Materials Processing Technology 211(6): 1146-1158. DOI: 10.1016/ j.jmatprotec.2011.01.018

12. Brandl, E., Schoberth, A., and Leyens, C. 2012. Morphology, microstructure, and hardness of titanium (Ti-6Al-4V) blocks deposited by wire-feed additive layer manufacturing (ALM). Materials Science and Engineering A 532(15): 295-307. DOI: 10.1016/j.msea.

2011.10.095

13. Fu, J., et al. 2017. Microstructure and mechanical properties of ti-6Al-4V fabricated by vertical wire feeding with axisymmetric multi-laser source. Applied Sciences 7(3): 227. DOI: 10.3390/ app7030 227

14. Henri, P., et al. 2012. Laser cladding with coaxial wire feeding. International Congress on Applications of Lasers \& Electro-Optics (ICALEO 2012): 1196-1201. Anaheim, Calif. DOI: 10.2351/1. 5062408

15. Brandl, E., Leyens, C., and Palm, F. 2011. Mechanical properties of additive manufactured Ti-6Al-4V using wire and powder based processes. IOP Conference Series: Materials Science and Engineering 26(1): 012004. DOI: 10.1088/1757-899x/26/1/012004

16. Martina, F., Mehnen, J., Williams, S. W., Colegrove, P., and Wang, F. 2012. Investigation of the benefits of plasma deposition for the additive layer manufacture of Ti-6Al-4V. Journal of Materials Processing Technology 212(6): 1377-1386. DOI: 10.1016/j.jmatprotec. 2012.02.002

17. Martina, F., Colegrove, P. A., Williams, S. W., and Meyer, J. 2015. Microstructure of interpass rolled wire + arc additive manufacturing Ti-6Al-4V components. Metallurgical and Materials Transactions A 46(12): 6103-6118. DOI: 10.1007/s11661-015-3172-1

18. Ho, A., et al. 2019. On the origin of microstructural banding in Ti-6Al4V wire-arc based high deposition rate additive manufacturing. Acta Materialia 166: 306-323. DOI: 10.1016/j.actamat. 2018.12.038

19. Gockel, J., Fox, J., Beuth, J., and Hafley, R. 2015. Integrated melt pool and microstructure control for Ti-6Al-4V thin wall additive manufacturing. Materials Science and Technology 31(8): 912- 916.

\section{DOI: 10.1179/1743284714y.0000000704}

20. Fuchs, J., Schneider, C., and Enzinger, N. 2018. Wire-based additive manufacturing using an electron beam as heat source. Welding in the World 62(2): 267-275. DOI: 10.1007/s40194-017-0537-7

21. 2018. Laserline GmbH, Fraunhofer Strasse, Mulheim-Karlich, Germany.

22. Elmer, J. W., Ellsworth, G. F., Florando, J. N., Golosker, I. V., and Mulay, R. P. 2017. Microstructure and mechanical properties of 21-6-9 stainless steel electron beam welds. Metallurgical and Materials Transactions A 48(4): 1771-1787. DOI: 10.1007/s11661-017-3996-y

23. Kou, S. 2002. Welding Metallurgy, $2^{\text {nd }}$ ed. New York, N.Y.: Wiley-Interscience.

24. Elmer, J. W., Allen, S. M., and Eagar, T. W. 1989. Microstructural development during solidification of stainless steel alloys. Metallurgical Transactions A 20(10): 2117-2131. DOI: 10.1007/ bf02650298

25. Katayama, S., and Matsunawa, A. 1984. Solidification microstructure of laser welded stainless steels. Proc. of ICALEO 1984: 60-67. DOI: 10.2351/1.5057623

26. Zhang, W., DebRoy, T., Palmer, and Elmer, J. W. 2005. Modeling of ferrite formation in a duplex stainless steel weld considering non-uniform starting microstructure. Acta Materiallia 53(16). DOI: 10.1016/j.actamat.2005.05.040

27. Suutala, N. 1983. Effect of solidification conditions on the solidification mode in austenitic stainless steels. Metallurgical Transactions A 14(1): 191-197. DOI: 10.1007/bf02651615

28. Hitzler, L., et al. 2017. On the anisotropic mechanical properties of selective laser-melted stainless steel. Materials 10(10): 1136. DOI: $10.3390 / \mathrm{ma10101136}$

29. Ledbetter, H. 1984. Monocrystal-polycrystal elastic constants of a stainless steel. Physica Status Solidi: 85-89. DOI: 10.1002/ pssa.2210850111

30. Kikuchi, M. 1971. Elastic anisotropy and its temperature dependence of single crystals and polycrystal of 18-12 type stainless steel. Transactions of the Japan Institute of Metals 12: 417-421. DOI: 10.2320/matertrans1960.12.417

31. Dewey, B. R., Adler, L., King, R. T., and Cook, K. V. 1977. Measurements of anisotropic elastic constants of type 308 stainless-steel electroslag welds. Experimental Mechanics 17(11): 420- 426. DOI: 10.1007/bf02324239

32. Florando, J. N., and Elmer, J. W. 2018. Unpublished work, Lawrence Livermore National Laboratory.

33. Kurz, W. 1986. Fundamentals of Solidification. Trans Tech Publications.

34. Wei, H. L., Elmer, J. W., and DebRoy, T. 2016. Origin of grain orientation during solidification of an aluminum alloy. Acta Materialia 115(15): 123-131. DOI: 10.1016/j.actamat.2016.05.057

35. Wei, H. L., Elmer, J. W., and DebRoy, T. 2017. Three-dimensional modeling of grain structure evolution during welding of an aluminum alloy. Acta Materialia 126: 413-425. DOI: 10.1016/j. actamat.2016.12.073

36. Wei, H. L., Elmer, J. W., and DebRoy, T. 2017. Crystal growth during keyhole mode laser welding. Acta Materialia 133: 10-20. DOI: 10.1016/j.actamat.2017.04.074

JOHN W. ELMER (elmer1@|Inl.gov) and GORDON GIBBS are with Lawrence Livermore National Laboratory, Livermore, Calif. JOHN S. CARPENTER, DANIEL R. COUGHLIN, and PAT HOCHANADEL are with Los Alamos National Laboratory, Los Alamos, N. Mex. JAY VAJA, PAROGYA GURUNG, and ANDY JOHNSON are with Aldermaston Weapons Establishment, Reading, Berkshire. MATTHEW J. DVORNAK is with Dvornak Consulting, Littleton, Colo. 